\title{
New Tmc1 Deafness Mutations Impact Mechanotransduction in Auditory Hair Cells
}

\author{
Maryline Beurg, ${ }^{1}$ Lisa A. Schimmenti, ${ }^{2}$ Alaa Koleilat, ${ }^{3}$ Sami S. Amr, ${ }^{4,7}$ Andrea Oza, ${ }^{5}$ Amanda J. Barlow, ${ }^{1}$ \\ Angela Ballesteros, ${ }^{6}$ and Robert Fettiplace ${ }^{1}$ \\ ${ }^{1}$ Department of Neuroscience, University of Wisconsin School of Medicine and Public Health, Madison, Wisconsin 53706, ${ }^{2}$ Departments of Clinical \\ Genomics, Otorhinolaryngology, Head and Neck Surgery and Biochemistry and Molecular Biology, Mayo Clinic School of Medicine, Rochester, Minnesota \\ 55902, ${ }^{3}$ Department of Laboratory Medicine and Pathology, Mayo Clinic, Rochester, Minnesota 55902, ${ }^{4}$ Laboratory for Molecular Medicine, Partners \\ HealthCare Personalized Medicine, Cambridge, Massachusetts 02139, ${ }^{5}$ Partners HealthCare Personalized Medicine, Laboratory for Molecular Medicine, \\ Cambridge, Massachusetts 02139, ${ }^{6}$ Molecular Physiology and Biophysics section, National Institute of Neurological Disorders and Stroke-National \\ Institutes of Health, Bethesda, Maryland 20892, and ${ }^{7}$ Department of Pathology, Brigham and Women's Hospital, Harvard Medical School, Boston, \\ Massachusetts 02115
}

Transmembrane channel-like protein isoform 1 (TMC1) is a major component of the mechano-electrical transducer (MET) channel in cochlear hair cells and is subject to numerous mutations causing deafness. We report a new dominant human deafness mutation, TMC1 p.T422K, and have characterized the homologous mouse mutant, Tmc1 p.T416K, which caused deafness and outer hair cell $(\mathrm{OHC})$ loss by the fourth postnatal week. MET channels showed decreased $\mathrm{Ca}^{2+}$ permeability and resting open probability, but no change in single-channel conductance or expression. Three adjacent deafness mutations are TMC1 p.L416R, p.G417R, and p.M418K, the last homologous to the mouse Beethoven that exhibits similar channel effects. All substitute a positive for a neutral residue, which could produce charge screening in the channel pore or influence binding of an accessory subunit. Channel properties were compared in mice of both sexes between dominant $(T m c 1$ p.T416K, Tmc1 p.D569N) and recessive (Tmc1 p.W554L, Tmc1 p.D528N) mutations of residues near the putative pore of the channel. Tmc1 p.W554L and p.D569N exhibit reduced maximum current with no effect on single-channel conductance, implying a smaller number of channels transported to the stereociliary tips; this may stem from impaired TMC1 binding to LHFPL5. Tmc1 p.D528N, located in the pore's narrowest region, uniquely caused large reductions in MET channel conductance and block by dihydrostreptomycin (DHS). For Tmc1 p.T416K and Tmc1 p.D528N, transduction loss occurred between P15 and P20. We propose two mechanisms linking channel mutations and deafness: decreased $\mathrm{Ca}^{2+}$ permeability, common to all mutants, and decreased resting open probability in low $\mathrm{Ca}^{2+}$, confined to dominant mutations.

Key words: cochlea; deafness; Hair cell; mechanotransduction channel; TMC1

Significance Statement

Transmembrane channel-like protein isoform 1 (TMC1) is thought to be a major component of the mechanotransducer channel in auditory hair cells, but the protein organization and channel structure are still uncertain. We made four mouse lines harboring Tmc1 point mutations that alter channel properties, causing hair cell degeneration and deafness. These include a mouse homolog of a new human deafness mutation $\mathrm{pT} 416 \mathrm{~K}$ that decreased channel $\mathrm{Ca}^{2+}$ permeability by introducing a positively-charged amino acid in the putative pore. All mutations are consistent with the channel structure predicted from modeling, but only one, p.D528N near the external face of the pore, substantially reduced channel conductance and $\mathrm{Ca}^{2+}$ permeability and virtually abolished block by dihydrostreptomycin (DHS), strongly endorsing its siting within the pore.

\footnotetext{
Received Sep. 29, 2020; revised Mar. 19, 2021; accepted Mar. 27, 2021.

Author contributions: M.B., L.A.S., A.B., and R.F. designed research; M.B., L.A.S., A.K., S.S.A., A.O., A.J.B., A.B., and R.F. performed research; M.B., L.A.S., A.K., S.S.A., A.O., A.J.B., A.B., and R.F. analyzed data; R.F. wrote the paper. This work was supported by National Institute on Deafness and other Communication Disorders Grants R01 DC015439 and R01 DC01362 (to R.F.). A.B. was supported by the National Institute of Neurological Disorders and Stroke Intramural Research Program Grant NS002945. A.K. was supported by the National Center for Advancing Translational Sciences Grant UL1 TR000135. L.A.S. was supported by the Mayo Clinic Center for Individualized Medicine and from the Mayo Clinic Department of Otorhinolaryngology.
}

The authors declare no competing financial interests.

Correspondence should be addressed to Robert Fettiplace at fettiplace@wisc.edu.

https://doi.org/10.1523/JNEUROSCI.2537-20.2021

Copyright $\odot 2021$ Beurg et al.

This is an open-access article distributed under the terms of the Creative Commons Attribution 4.0 International license, which permits unrestricted use, distribution and reproduction in any medium provided that the original work is properly attributed. 
A
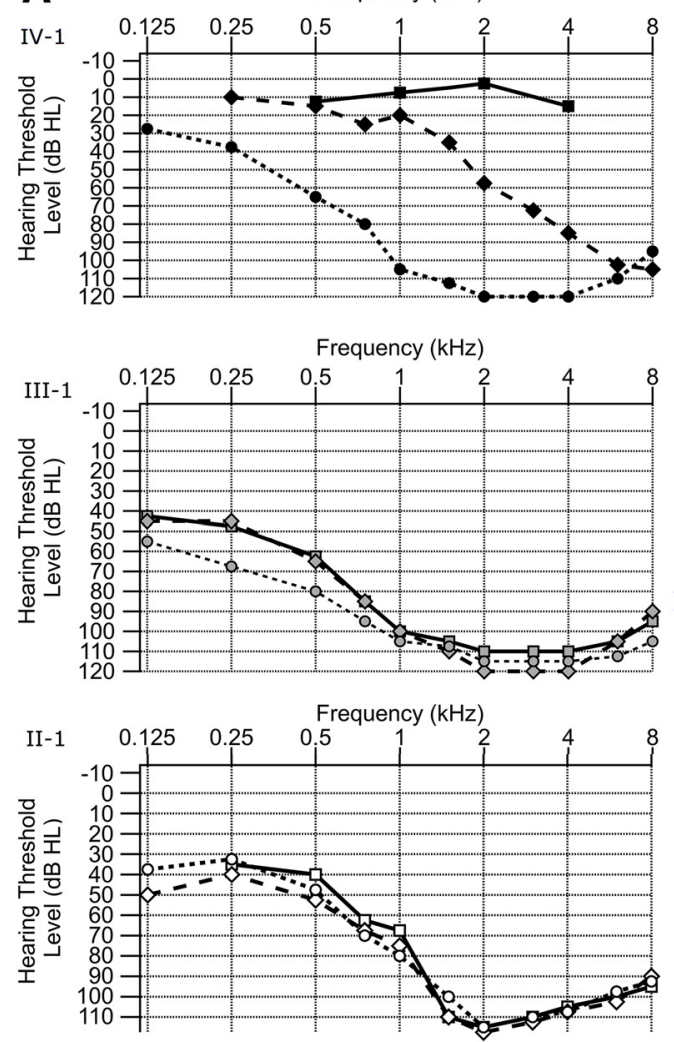

B$$
\text { . }
$$
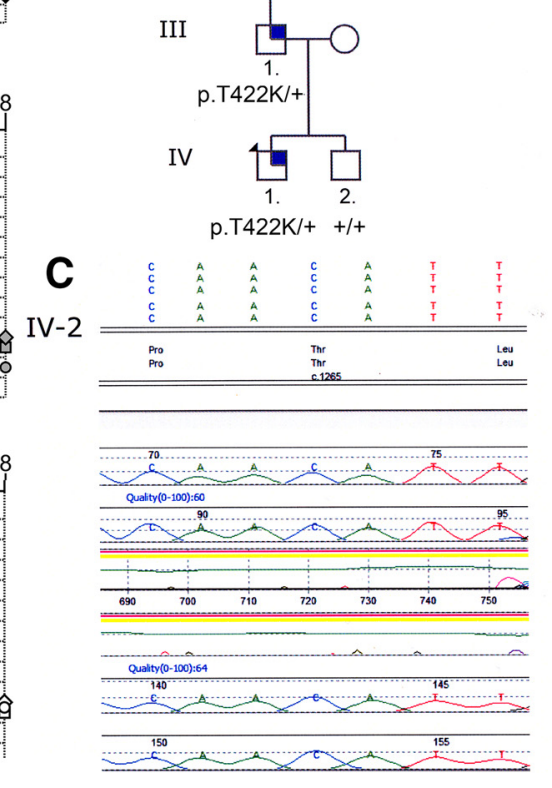

\section{D}
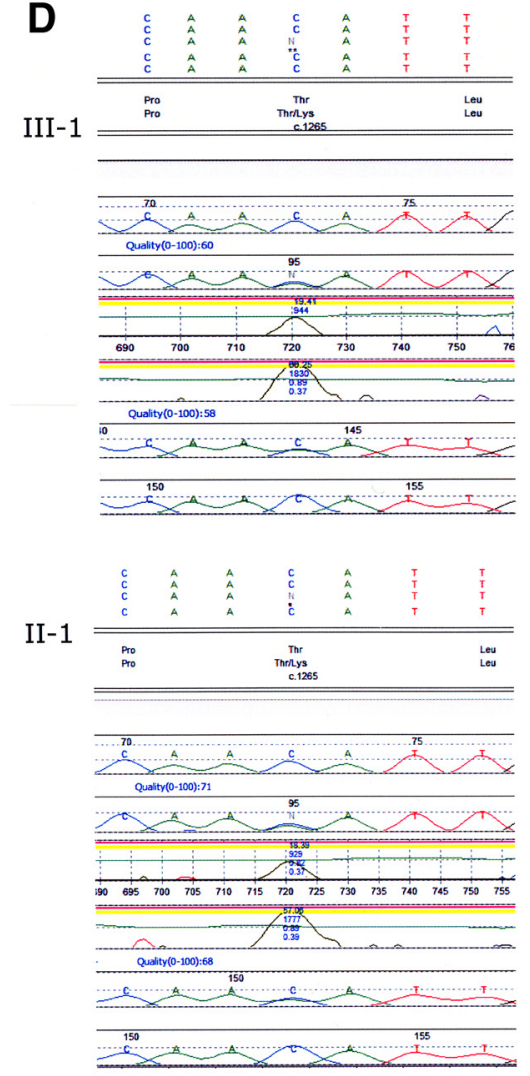

Figure 1. Genotype and phenotype of family. A, Audiogram of the proband (top graph with filled in black markers), father (middle graph with filled in gray markers), grandmother (bottom graph with unfilled markers). Three time points are indicated (T1, rectangle; $\mathrm{T} 2$, diamond; $\mathrm{T} 3$, circle) for each individual. Each point on the graph is the average hearing threshold from the right and left ear. The proband was five years old at T1 and shows normal hearing at 0.5, 1, 2, and $4 \mathrm{kHz}$. At the second evaluation (T2), the patient was 11 years old and shows normal hearing from 0.25 to $1 \mathrm{kHz}$ with hearing loss starting at $1.5 \mathrm{kHz}$. At T3, the patient was 14 years old and illustrates profound to severe hearing loss at all of the frequencies. The father shows moderate to profound hearing loss at all time points. Father was 37 years old at T1, 38 years old at T2, and 39 years old at T3. The grandmother also shows moderate to profound hearing loss at all frequencies. Her age was 57 years old at $\mathrm{T} 1$ and 58 years old at $\mathrm{T} 2$ and $\mathrm{T} 3$. $\boldsymbol{B}$, Pedigree of the family indicating autosomal dominant transmission pattern. Circles are indicative of a female and squares of a male. An individual with a filled in blue corner indicates that they report some degree of hearing loss. C, DNA sequencing data for unaffected brother. D, DNA sequencing data for father III-1 and grandmother II-1 both with hearing loss.

\section{Introduction}

Sound detection occurs in the cochlea where evoked mechanical stimuli are translated into electrical signals by the gating of mechano-electrical transducer (MET) channels in the stereocilia of sensory hair cells (Fettiplace, 2017). A bundle of 50-100 stereocilia arranged in three or four rows of increasing height projects from the endolymphatic surface of each hair cell. The MET channels, located at the lower end of each tip link, are activated by force delivered via interciliary tip links (Pickles et al., 1984; Assad et al., 1991; Beurg et al., 2009). The MET channel is thought to be formed principally by the transmembrane channel-like protein isoform 1 (TMC1) protein (Kawashima et al., 2011; Kim and Fettiplace, 2013; Pan et al., 2018), with additional proteins serving as accessory subunits; these include LHFPL5 (Xiong et al., 2012), TMIE (Zhao et al., 2014a; Pacentine and Nicolson, 2019; Cunningham et al., 2020), and CIB2 (Giese et al., 2017). There are at least 35 reported point mutations (pathogenic variants) of the TMC1 gene causing human deafness (Yue et al., 2019), underscoring the key role of TMC1 in sound transduction. These mutations are divided into two categories, those referred to as DFNA36 that are autosomal dominant, and those labeled DFNB7/11 that are autosomal recessive (Kurima et al., 2002). A previously described dominant mouse mutation, Tmc1 p.M412K (Beethoven), leads to early hearing loss and hair cell degeneration (Vreugde et al., 2002). The homologous human deafness mutation is TMC1 p.M418K (Zhao et al., 2014b; Wang et al., 2018), the mutation site is adjacent to two other missense mutations causing deafness: TMC1 p.L416R (Chen et al., 2015) and TMC1 p.G417R (Yang et al., 2010). Here we report a fourth deafness mutation in the same region, TMC1 p.T422K and we generate and characterize the homologous mouse mutation Tmc1 p.T416K.

The phenotypic changes in MET channel properties in Tmc1 p.M412K have been well described (Vreugde et al., 2002; Marcotti et al., 2006; Pan et al., 2013; Beurg et al., 2015a; Corns et al., 2016) but the mechanism leading to hair cell degeneration and death is unknown. The decrease in MET channel $\mathrm{Ca}^{2+}$ permeability in Tmc1 p.M412K is semi-dominant, the heterozygous possessing a permeability intermediate between the wild type and homozygote (Corns et al., 2016; Beurg et al., 2019). Localization of the mutation site has been gleaned from recent modeling of the TMC1 protein structure based on its relationship with TMEM16 chloride channels and lipid scramblases, which have 10 transmembrane (TM) domains (Ballesteros et al., 2018; Pan et al., 2018). This modeling suggests that the pore cavity is formed by TM domains TM4 to TM7, and maps the region containing the string of four mutants to TM4. Several sites crucial for MET channel performance have been identified by adenovirus-mediated expression of TMC1 containing cysteine substitutions in neonatal mice, and then treating cultured cochleas with cysteine modification reagents (Pan et al., 2018). We have extended that work using the CRISPR/Cas9 technology to 

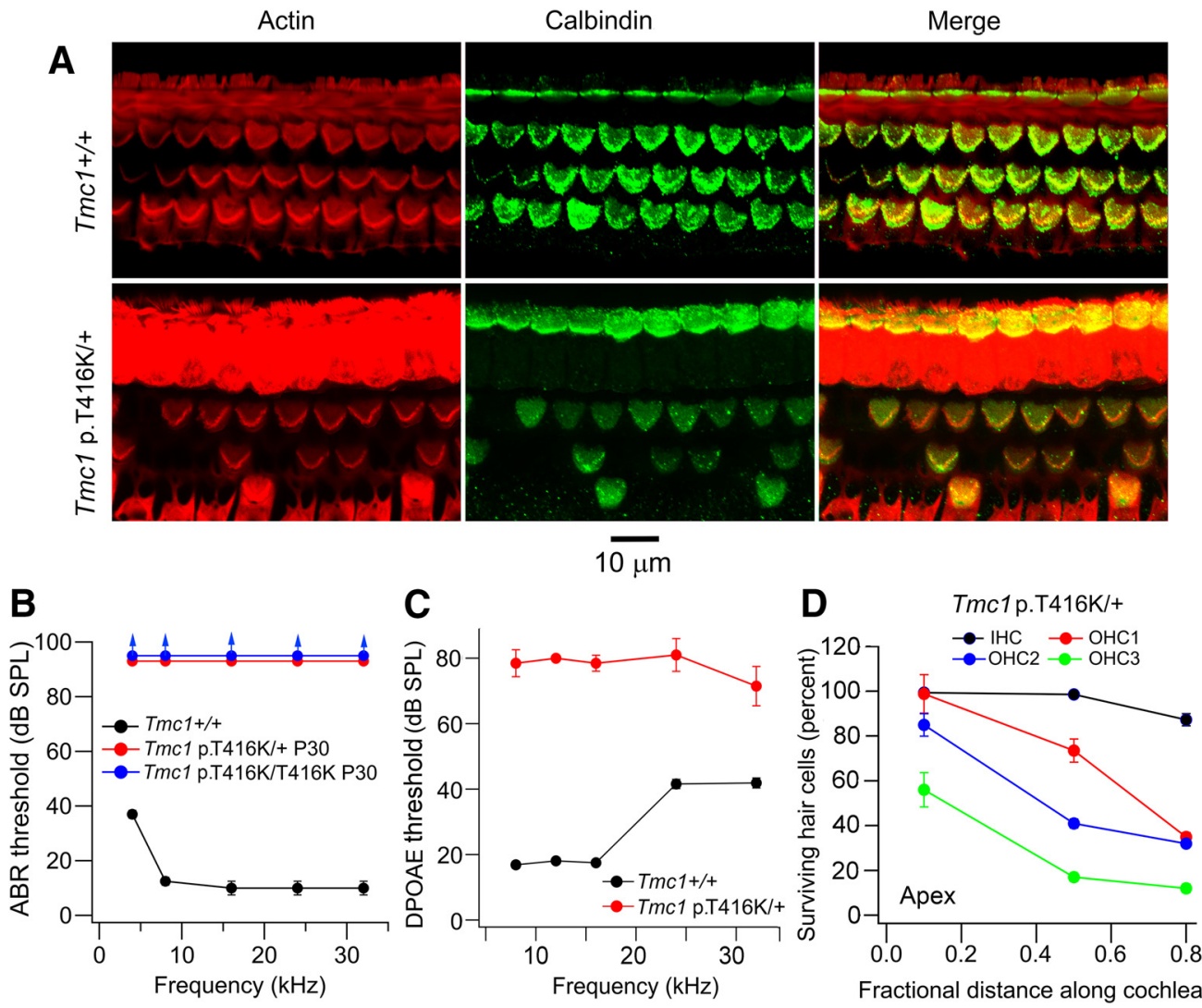

Figure 2. Auditory phenotype of mouse $\operatorname{Tmc} 1$ p.T416K; $T m c 2+/+$. A, Fixed whole mounts of mid-region of cochleas of P30 Tmc $1+/+$ (top row) and Tmc1 p.T416K/+ (bottom row) labeled with phalloidin (Actin), calbindin28K (cell somas) and merge. Note OHC loss in mutant. B, ABRs thresholds of P30 wild-type, Tmc1 p.T416K/T416K homozygote, and Tmc1 p.T416K/+ heterozygote showing dominant phenotype. C, DPOAEs thresholds for Tmc1+/+ (black symbols, N=6) and Tmc1 p.T416K/+ (red symbols, N=8). D, Hair cell survival in P30 Tmc1 p.T416K/+ heterozygote. For each cell type, $\sim 100$ cells along the cochlea were included in the count to construct average. In each panel, the mean $+/-$ SD is plotted.

generate mice with missense mutations in TMC1, which enabled us to characterize the deafness phenotype, whether dominant or recessive, and possible mechanism relating to hearing loss in the unaltered endogenous tissue. We also examined the stitch mutant mouse, Tmc1 p.W554L (Manji et al., 2012), which is located at the intracellular loop joining TM6 and TM7 in the TMC1 model. We compare its properties with those of other deafness mutants Tmc1 p.D569N (Beurg et al., 2019) and $T m c 1$ p.D528N. These experiments together address the assumptions that TMC1 is the major component of the MET channel and that the region comprising TM4 to TM7 at least partly dictates ionic performance.

\section{Materials and Methods}

Human subjects

The Mayo Clinic Institutional Review Board (IRB) provided approval for this study.

\section{Mouse mutants}

Tmc1 p.D569N and Tmc1 p.W554L mutant mice were made by Applied StemCell Inc (Beurg et al., 2019) and Tmc1 p.D528N and Tmc1 p.T416K mice were made by Horizon Sage Labs Inc, all using CRISPR/Cas9 technology. For all four genotypes, mutations were verified by 500 base pair sequencing around the mutation site, and mice were subsequently bred for five generations, after which any off-target effects should have been eliminated. Tmc1 p.M412K Beethoven mice were a gift of Walter Marcotti (Sheffield University, United Kingdom) and Karen Steel (Kings College London, United Kingdom). All Tmc1 mutants for which hair cell transduction was characterized were performed on a Tmc2-/background to avoid complications because of different channel properties of TMC2 (Kim et al., 2013; Kim and Fettiplace, 2013). Tmc2-/- mice (B6.129S5-Tmc $2^{\text {tm1Lex }} / \mathrm{Mmucd}$ ) were obtained from the Mutant Mouse Regional Resource Center (University of California, Davis, CA). Neonatal mice were killed by decapitation according to the animal protocol approved by the Institutional Animal Care and Use Committee at the University of Wisconsin-Madison. For all strains, a mixture of male and female mice was used and no gender-specific effects were noted. Acoustic brainstem responses (ABRs) and distortion product otoacoustic emissions (DPOAEs) were measured on postnatal day (P)30 and P60 mutants and P30 wild-type mice, anesthetized with $10 \mathrm{mg} / \mathrm{ml} \mathrm{ketamine} \mathrm{plus} 1 \mathrm{mg} / \mathrm{ml}$ xylazine and using Tucker-Davis Technology Auditory Workstation. Preyer (pinna twitch) reflexes were evoked using an Oxefly dog-training clicker to detect hearing in P15P21 mice that were too young for ABR measurements. The clicker was place $\sim 10 \mathrm{~cm}$ from the back of the head.

\section{Hair cell survival}

To document hair cell survival in mutants, isolated cochleas were fixed in $4 \%$ paraformaldehyde for $1 \mathrm{~h}$ at room temperature, processed (Beurg et al., 2019) and immunolabeled with rabbit monoclonal anticalbindinD28k (Swant, 1:500, 2 h), and Alexa Fluor 568 phalloidin. Mounted preparations were viewed with a $60 \times$ Plan apochromat $(\mathrm{NA}=1.4)$ on a Nikon A1 laser-scanning confocal microscope, and fluorescence intensity was quantified with ImageJ. Two methods were used to assay the number of functional MET channels in mutants: immunolabeling of TMC1 (Beurg et al., 2015b) and hair cell accumulation of the permeant FM1-43 (Gale et al., 2001). For TMC1 immunolabeling, cochleas of P6 mice were fixed in 4\% paraformaldehyde for $30 \mathrm{~min}$ followed by permeabilization in $0.5 \%$ Triton for $30 \mathrm{~min}$ at room temperature, then incubated in $10 \mathrm{~mm}$ Na citrate, $\mathrm{pH} 6.0,75^{\circ} \mathrm{C}$ for $30 \mathrm{~min}$. Fixed cochleas were subsequently immersed in $10 \%$ normal goat serum for $1 \mathrm{~h}$ at room temperature and incubated overnight at $4^{\circ} \mathrm{C}$ with the primary 
A
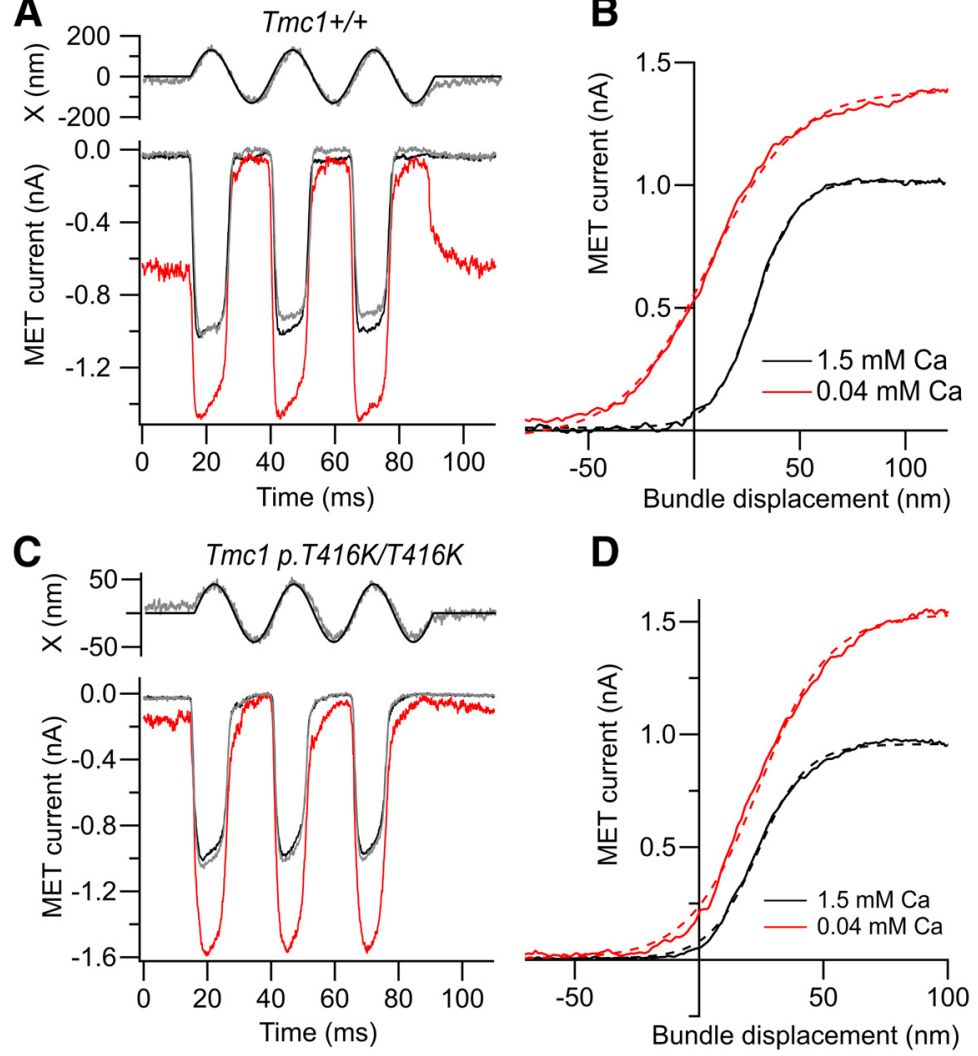

Figure 3. MET currents of apical OHCs for control and p.T416K mutant mice. $\boldsymbol{A}$, MET currents in response to bundle vibration in $\operatorname{TmC} 1+/+; \operatorname{Tmc2}-/-$ in saline containing $1.5 \mathrm{~mm} \mathrm{Ca}^{2+}$ (black, gray before and after) and endolymphlike $0.04 \mathrm{~mm} \mathrm{Ca}^{2+}$ (red); top trace is driving voltage to piezo (smooth curve) superimposed on photodiode signal (noisy gray trace). $\boldsymbol{B}$, Current-displacement relations evaluated from responses in $\boldsymbol{A}$ for $1.5 \mathrm{~mm} \mathrm{Ca}^{2+}$ (black) and 0.04 $\mathrm{mm} \mathrm{Ca}{ }^{2+}$ (red). Lowering external $\mathrm{Ca}^{2+}$ increased maximum current $I_{\text {MAx }}$ and fraction on at rest. Dashed curves are fits of current I against displacement $x$ to Boltzmann equation: $I=I_{\text {MAX }} /[1+\exp ((x 1-x) / a)]$, where $I_{\text {MAX }}=1.0 \mathrm{nA}$, $\mathrm{a}=9.8 \mathrm{~nm}, \mathrm{x} 1=29 \mathrm{~nm}\left(1.5 \mathrm{Ca}^{2+}\right)$ and $I_{\text {MAX }}=1.43 \mathrm{nA}, \mathrm{a}=21 \mathrm{~nm}, \mathrm{x} 1=6.9 \mathrm{~nm}\left(0.04 \mathrm{Ca}^{2+}\right)$. C, MET currents in response to bundle vibration in Tmc1 p.T416K/T416K; Tmc2-/- mice in saline containing $1.5 \mathrm{~mm} \mathrm{Ca}^{2+}$ (black, gray before and after) and endolymph-like $0.04 \mathrm{~mm} \mathrm{Ca}{ }^{2+}$ (red); top trace is driving voltage to piezo (smooth curve) superimposed on photodiode signal (noisy gray trace). $\boldsymbol{D}$, Current-displacement relations evaluated from responses in $\boldsymbol{C}$ for $1.5 \mathrm{mM} \mathrm{Ca}^{2+}$ (black) and $0.04 \mathrm{~mm} \mathrm{Ca}^{2+}$ (red). Dashed curves are fits to Boltzmann equation, where $I_{\mathrm{MAX}}=0.98 \mathrm{nA}$, $\mathrm{a}=10.4 \mathrm{~nm}, \mathrm{x} 1=23 \mathrm{~nm}\left(1.5 \mathrm{Ca}^{2+}\right)$ and $\mathrm{I}_{\text {MAX }}=1.56 \mathrm{nA}, \mathrm{a}=14.7 \mathrm{~nm}, \mathrm{x} 1=23.6 \mathrm{~nm}\left(0.04 \mathrm{Ca}^{2+}\right)$. Note that in mutant, low $\mathrm{Ca}^{2+}$ still increases maximum current but has smaller effect on resting open probability, and no effect on $\mathrm{x} 1$, i.e., no shift in the activation curve; holding potential $-84 \mathrm{mV}$. The difference in resting open probability between control, and mutant was not seen in $1.5 \mathrm{~mm}$ extracellular $\mathrm{Ca}^{2+}$ (see text).

anti-TMC1 affinity-purified antibody (HPA 044166, made against a 39residue N-terminal human TMC1 sequence; Sigma-Aldrich) at 1:50 dilution, followed by anti-rabbit Alexa Fluor 488 secondary antibody. Mounted preparations were viewed with a $60 \times$ Plan apochromat $(\mathrm{NA}=1.4)$ on a Nikon A1 laser-scanning confocal microscope, and fluorescence intensity was quantified with ImageJ. Each immunolabeling run was performed on three cochleas from different animals, and the process was repeated two times, so six animals in total were used for each labeling procedure.

FM1-43 staining was performed on apical turns of unfixed cochlear explants of P15, P20, and P30 mice using labeling procedures described previously (Vélez-Ortega et al., 2017; Krey et al., 2020). Animals were anesthetized with isoflurane then decapitated according to the animal protocol approved by the Institutional Animal Care and Use Committee at the University of Wisconsin-Madison. A piece of temporal bone was excised and held in a thin slice of SILASTIC tubing $(\sim 3 \mathrm{~mm}$ in diameter) glued to a coverslip (Mahendrasingam et al., 2010). The apical turn of the cochlea was exposed and opened, Reissner's membrane removed and the cochlear apex perfused with $0.1 \mathrm{mg} / \mathrm{ml}$ protease (type XXIV, Sigma-Aldrich) for $2 \mathrm{~min}$ to loosen the tectorial membrane but not to remove it. It was then incubated for $2 \mathrm{~min}$ in $0.1 \mathrm{~mm}$ tubocurarine [to block remaining MET channels, sometimes supplemented with $1 \mathrm{~mm}$ dihydrostreptomycin (DHS)] followed by $30 \mathrm{~s}$ in ice-cold HBSS supplemented with $6 \mu \mathrm{M}$ FM1-43 (ThermoFisher) in the presence or absence of $0.1 \mathrm{~mm}$ tubocurarine, then washed in HBSS. The FM1-43 solution was ice cold to inhibit uptake by a metabolically sensitive endocytic mechanism. The preparation was observed on a Leica DMLFS top-focusing microscope with a $40 \times$ waterimmersion objective (NA $=0.8)$ and imaged with an Orca camera (Hamamatsu Corporation). The mean fluorescence intensity was quantified with ImageJ in a region of interest extending to the edge of the cell, below the cuticular plate, about half-way down the OHCs and in the crook of the IHC soma where it bends toward the modiolus. The focal plane was often different for the two types of hair cell. The camera gain setting was kept constant across the different manipulations: genotypes with and without channel blocker.

\section{Hair cell recording and stimulation}

MET currents were recorded from inner hair cells (IHCs) and outer hair cells (OHCs) in isolated organs of Corti of mice between $\mathrm{P} 2$ and $\mathrm{P} 8$ as previously documented (Kim et al., 2013; Beurg et al., 2019). Preparations were mounted on the stage of a Leica DMLFS top-focusing microscope and viewed with $40 \times(\mathrm{NA}=0.8)$ objective and a $2 \times$ optivar. Most recordings were from the apical (low frequency) turn, $\sim 70 \%$ of the distance along the cochlea from the stapes. The recording chamber was perfused with saline: $152 \mathrm{~mm} \mathrm{NaCl}, 6 \mathrm{~mm} \mathrm{KCl}, 1.5$ $\mathrm{mm} \mathrm{CaCl} 2,2 \mathrm{~mm}$ Na-pyruvate, $8 \mathrm{~mm}$ D-glucose, and $10 \mathrm{~mm}$ Na-HEPES, pH 7.4. In some experiments, saline of reduced $(0.04 \mathrm{~mm}) \mathrm{CaCl}_{2}$ was perfused over the preparation to replace the normal $(1.5 \mathrm{~mm})$ $\mathrm{CaCl}_{2}$. In this type of experiment, the fluid jet initially contained saline with normal $\mathrm{Ca}^{2+}$, but on perfusing the bath with $0.04 \mathrm{~mm} \mathrm{Ca}^{2+}$, the fluid jet tip was filled with the low $\mathrm{Ca}^{2+}$ by sucking the bath solution back through its tip for $30 \mathrm{~s}$ (Corns et al., 2016). The effectiveness of the solution exchange was confirmed by additional experiments using bundle deflections with a glass probe. Furthermore, the increase in current in low $\mathrm{Ca}^{2+}$ in OHCs of $T m c 1+/+$ using the fluid jet $(1.54 \pm 0.10)$ agreed quantitatively with our previous measurements $(1.52 \pm 0.12)$ using only a glass probe stimulator (Beurg et al., 2006). For determining channel block by DHS, a similar approach to that with low $\mathrm{Ca}^{2+}$ was followed; results derived from fluid jet stimulation were confirmed with stimulation with a stiff glass probe and the points from two methods plotted as different symbols on the Hill plot. Patch electrodes were filled with the following: $142 \mathrm{~mm} \mathrm{CsCl}$, $3.5 \mathrm{~mm} \mathrm{MgCl}$, $5 \mathrm{~mm} \mathrm{Na}_{2} \mathrm{ATP}, 0.5 \mathrm{~mm} \mathrm{Na} \mathrm{GTP}_{2}, 10 \mathrm{~mm}$ Tris phosphocreatine, $1 \mathrm{~mm}$ 1,2-bis(o-aminophenoxy) ethane- $N, N, N^{\prime}, N^{\prime}$-tetraacetic acid (BAPTA), and $10 \mathrm{~mm}$ Cs-HEPES, pH 7.2, and were connected to an Axopatch 200B amplifier. Electrode series resistances with $60 \%$ compensation were at best $3 \mathrm{M} \Omega$, which together with a $\sim 5 \mathrm{pF}$ cell capacitance gave recording time constants of $15 \mu \mathrm{s}$. Whole-cell currents were lowpass filtered with an eight-pole filter set to $5 \mathrm{kHz}$.

Stereociliary bundles were stimulated with a fluid jet from a pipette with a $\sim 10 \mu \mathrm{m}$ in diameter tip or with a glass probe driven by a piezoactuator. The amplitude and time course of bundle motion was in some experiments calibrated by projecting the bundle image onto a pair of photodiodes and measuring the onset of the photocurrent (Crawford and Fettiplace, 1985; Ricci et al., 2005). Single MET-channel events were recorded in whole-cell mode after brief exposure of the bundle to saline containing $5 \mathrm{~mm}$ BAPTA plus $2.5 \mathrm{~mm} \mathrm{Ca}^{2+}$ (Beurg et al., 2006, 2018). 
For all mutants, a subconductance state about half the amplitude of the full state was sometimes seen in a fraction of the traces (Beurg et al., 2018), but these events were not included in the amplitude histograms. Histograms of channel amplitude were fit with two Gaussians using a routine in IGOR Pro v8 (Wavemetrics). The $\mathrm{Ca}^{2+}$ selectivity of the MET channel relative to $\mathrm{Cs}^{+}$was determined from $\mathrm{Ca}^{2+}$-reversal potentials of the MET current measured in an extracellular solution containing the following: 100 $\mathrm{mm} \mathrm{CaCl}, 20 \mathrm{~mm} \mathrm{~N}$-methylglucamine, and 5 mм Tris, $\mathrm{pH}$ 7.4, and an intracellular Cs-based solution (see above). Reversal potentials were corrected for a $-9 \mathrm{mV}$ junction potential and were analyzed using the Goldman-HodgkinKatz (GHK) equation with activity corrections applied to the ion concentrations (Beurg et al., 2006; Kim et al., 2013). Experiments were performed at room temperature, $21-23^{\circ} \mathrm{C}$.

\section{Statistical test}

All results are quoted as mean \pm 1 SD and statistical tests used a two-tailed $t$ test, significance tests indicated as: $* p<0.05, \quad * * p<0.01$, $* * * p<0.001$. ABRs and DPOAEs and immunologic labeling were performed on at least four mice for each mutation. MET currents were recorded and single channel conductance values were determined on four or more mice for each mutant. The FM1-43 assays for mechanotransduction were performed on two or three mice for each condition.

Next generation sequencing (NGS) of the proband on the OtoGenome panel

Targeted NGS was performed at the Laboratory for Molecular Medicine (Harvard Partners) on the OtoGenome platform (at the time of testing, the OtoGenome consisted of a targeted panel of 87 validated hearing loss genes) as previously described (Mandelker et al., 2014). DNA was extracted from peripheral blood lymphocytes using the Puregene genomic DNA isolation kit (QIAGEN). The gene panel test was performed by NGS using oligonucleotide-based target capture (Agilent SureSelect; Agilent Technologies, Santa Clara, CA), followed by Illumina HiSeq (Illumina Inc.) sequencing of the coding regions and splice sites of 87 genes associated with nonsyndromic hearing loss. Alignment and variant calling for single nucleotide variants and indels were determined with the Burrows-Wheeler Aligner and Genome Analysis Toolkit Unified Genotyper and copy number analysis was performed using an in-house developed tool (Pugh et al., 2016). Variants detected were assessed for pathogenicity and classified based on American College of Medical Genetics and Genomics criteria (Richards et al., 2015). Sanger sequencing was performed on family members as described previously (Zimmerman et al., 2010), using primers targeting exons 16-17 of HsTMC1 (NM_138691.2) which encompass the c.1265C $>$ A (p.T422K). The sequencing primers are: forward, $5^{\prime}-$ CCAAAATTCTGGCAAAAAGC-3' and reverse, 5'-CATGAAATT CAGAGCCAGCA-3'.

Localization of the deafness-causing mutations in TMC1

The TMC1 model was based on the Nectria hematococca TMEM16 structure (PDB ID: 4WIS; Ballesteros et al., 2018), but the intracellular TM6-TM7 loop containing residue W554 was not included in the original model because of the limited sequence homology with the template. We therefore modeled this intracellular loop in mTMC1 by using the loop modeling tools of I-TASSER (Yang et al., 2015) and SWISSMODEL (Waterhouse et al., 2018), which build the loop by ab initio modeling. The global root mean square deviation (RMSD) between the two models was $3.5 \AA$ for the 150 residues comprising the TM4-TM7 region as calculated by SuperPose (http://wishart.biology.ualberta.ca/ SuperPose/), PROCHECK (Laskowski et al., 1993) was used to analyze the stereochemical quality of each model. The TMC1 model containing the TM6-TM7 loop generated by SWISS-MODEL presented better Ramachandran Plot statistics and lower G-factors to that generated by ITASSSER, and was thus selected as the best model to depict residue W554. We used the PPM server (Lomize et al., 2012) to position and orient the TMC1 model in a lipid bilayer of adjustable thickness by minimizing its transfer energy from water to the membrane. The membrane building tool of CHARMM-GUI (Jo et al., 2008; Wu et al., 2014) was then used to generate and assemble the lipid bilayer and measure the pore size. UCSF Chimera v1.14 (Pettersen et al., 2004) software was used to visualize the structures and generate the final figures.

\section{Results}

\section{Human TMC1 p.T422K pathogenic variant}

A new TMC1 missense pathogenic variant, TMC1 p.T422K, was found in a family whose four-generation family history of hearing was evaluated (Fig. 1). The proband, an 11-year-old boy, presented with bilateral high frequency sensorineural hearing loss. He was born at term without complications and passed newborn hearing screening. Audiometric testing, at the time of presentation, demonstrated normal hearing from 250 to $1000 \mathrm{~Hz}$, sloping to profound loss at $6000 \mathrm{~Hz}$ [Fig. $1 A, \mathrm{IV}-1$, pure tone average (PTA) of both ears, dashed line]. Review of previous records showed a normal audiogram at five years of age at all four frequencies tested $(0.5,1,2$, and $4 \mathrm{kHz}$; Fig. $1 A$, solid line). At age 14 , his audiogram showed moderate-severe hearing loss between 125 and $250 \mathrm{~Hz}$ and profound loss from 500 to $8000 \mathrm{~Hz}$ (Fig. 1A, IV-1 dotted line). He underwent unilateral left sided cochlear implantation, as hearing aids no longer provided benefit. He was 


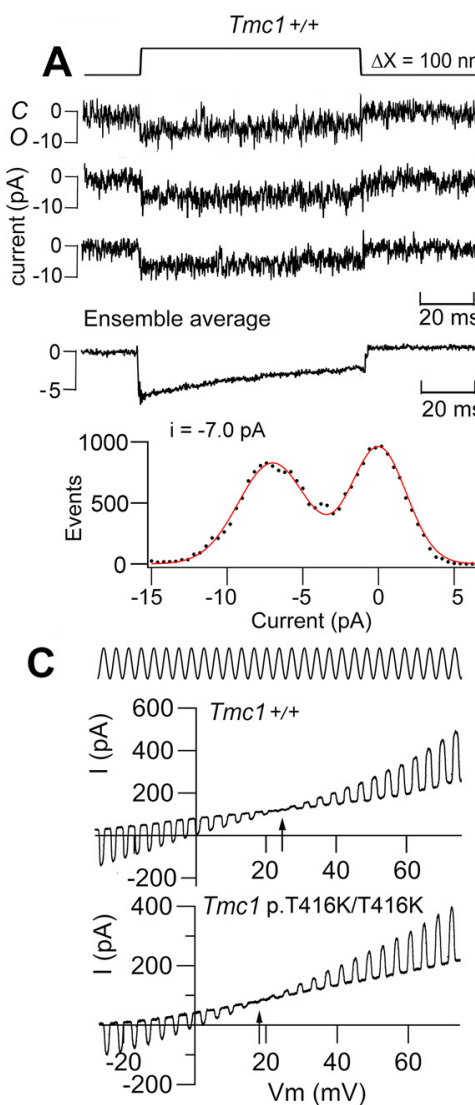

E
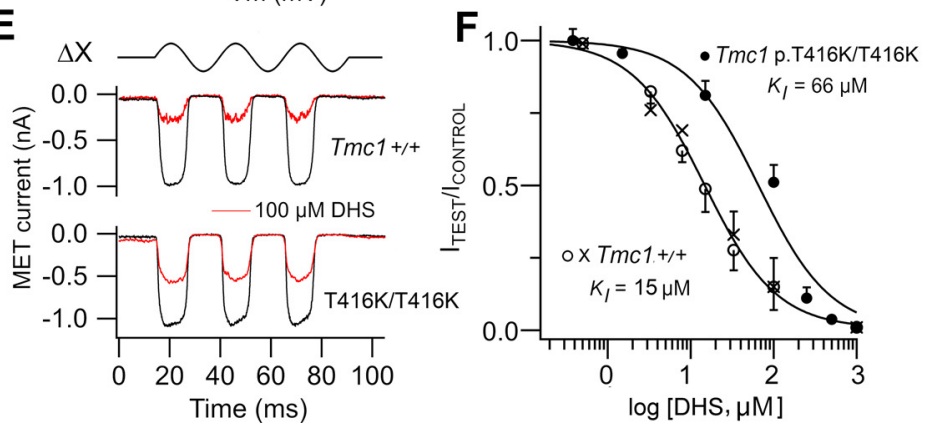

Figure 5. Ionic properties of MET channels from apical OHCS of Tmc1 p.T416K/T416K; Tmc2-/-. A, Three examples of single MET channel currents for $\operatorname{TmC} 1+/+$; $\operatorname{TmC} 2-/$-, ensemble average of 30 presentations (middle) and amplitude histogram (bottom) giving $-7.0 \mathrm{pA}$ at $-84 \mathrm{mV}$. C and 0 indicate closed and open states of channel. $\boldsymbol{B}$, Examples of single MET channel currents for Tmc1 p.T416K/T416K; Tmc2-/-, ensemble average of 100 presentations (middle) and amplitude histogram (bottom) giving $-7.0 \mathrm{pA}$ at $-84 \mathrm{mV}$. C, Determination of MET channel $\mathrm{Ca}^{2+}$ permeability in isotonic external $\mathrm{Ca}^{2+}$ and internal $C s^{+}$(see Materials and Methods). During a sinusoidal bundle vibration $(\Delta X, \pm 200 \mathrm{~nm})$, the membrane potential $\left(V_{m}\right)$ was swept from -30 to $+80 \mathrm{mV}$ and the MET current reversed polarity at arrowed potential. Reversal potential in Tmc1 +/+; Tmc2-/- is $\sim 7 \mathrm{mV}$ positive to that in Tmc1 p.T416K/T416K; Tmc2-/-. D, Collected reversal potentials and relative permeability $\mathrm{P}_{\mathrm{Ca}_{\mathrm{a}}} / \mathrm{P}_{\mathrm{Cs}}$ in six cells mean $+/-\mathrm{SD}$. Control and mutant are significantly different $(t$ test, $* * * p<$ 0.001). $E$, MET currents for bundle vibrations $(\Delta X, \pm 200 \mathrm{~nm})$ in normal saline (black traces) and in presence of $100 \mu \mathrm{m}$ DHS in Tmc1 +/+; Tmc2-/- (top) and Tmc1 p.T416K/T416K; Tmc2-/- (bottom). F, Mean \pm SD $(N=5)$ of MET current block by DHS in Tmc1+/+ and Tmc1 p.T416K/T416K. Hill plots give $\mathrm{K}_{\mathrm{I}}=15 \mu \mathrm{m}$ (all points) and $66.0 \mu \mathrm{m}$, respectively, with Hill coefficients $=1$ for both genotypes. For control curve, open symbols determined using bundle stimulation with a fluid et $\left(K_{I}=14.0 \mu \mathrm{m}\right)$, whereas crosses obtained with a stiff glass probe $\left(K_{I}=15.4 \mu \mathrm{m}\right)$. The similar $K_{I}$ values for the different jstimulation methods rules out artifacts because of dilution of DHS by saline in the fluid jet.

otherwise healthy and met his developmental milestones on time and had no balance issues. However, his speech was notable for disarticulations suggesting long standing hearing loss. Genetic testing was performed using the OtoGenome panel, a targeted hearing loss panel that at the time, sequenced 87 known hearing loss genes. Testing identified three single heterozygous variants of unknown significance, specifically OTOGL c.2138C $>$ A
(p.A713D), TMC1 c.1265C $>$ A (p.T422k), and TMIE c.101C $>$ T (p.T34M). As both OTOGL and TMIE are known as recessive genes, the likelihood of contributing to the proband's hearing loss was less as a second allele was not identified. TMC1 mutations can be inherited as autosomal dominant as well as recessive. Threonine, an amino acid with a polar, uncharged side chain, is conserved in mouse, chicken, and platypus at this orthologous position (ensembl.org). In addition, the variant in TMC1 was absent from large population databases (https://gnomad. broadinstitute.org/).

\section{Father of proband (III-1)}

The proband's father was 37 years old at the time of presentation. He was diagnosed with hearing loss at age 15 after failing a school hearing screening examination. Review of audiograms from three time points over a threeyear period from age 37 to 39 were essentially unchanged and showed down sloping moderate-severe to profound hearing loss (Fig. 1A, III-1). He underwent cochlear implantation at age 39. Allele-specific genetic testing showed that he had the same heterozygous variant in TMC1, c. $1265 \mathrm{C}>\mathrm{A}$ (p.T422K; Fig. 1D, III-1).

\section{Grandmother of proband (II-1)}

The proband's paternal grandmother was 56 years old at the time of presentation. She reported bilateral hearing loss starting in her early twenties with progression over time. Audiograms at three time points, between ages 57 and 58, revealed PTA in the moderate to profound range from 125 to $1500 \mathrm{~Hz}$ with no responses from $2000-8000 \mathrm{~Hz}$ (Fig. $1 A$, II-1). She underwent cochlear implantation at age 58. Allele-specific genetic testing showed that she had the same heterozygous variant in TMC1, c.1265C>A (p.T422K; Fig. 1D, II-1).

\section{Brother of proband (IV-2)}

The proband's brother was 12 years old at the time of evaluation and no hearing abnormalities were reported. He passed the newborn hearing screening, and had normal audiograms at 3,9 , and 10 years. Allele-specific genetic testing showed bi-allelic normal copies of TMC1 (Fig. 1C).

Murine Tmc1 p.T416K deafness-causing mutation

A mouse model carrying the homologous mutation of TMC1 p.T422K, Tmc1 p.T416K, was generated using CRISPR/Cas9 
technology (see Materials and Methods) and characterized using hair cell survival (Fig. 2A), ABRs (Fig. 2B), and otoacoustic emissions (Fig. 2C). ABRs revealed profound hearing loss across the entire frequency spectrum in both homozygotes and heterozygotes at P30, consistent with the dominance of the human mutation. Degeneration and absence of OHCs was evident at P30 (Fig. 2A,D), with the base being more affected than the apex at that age, as with many cochlear insults (Fettiplace and Nam, 2019). Despite loss of fewer OHCs at the apex, it is likely that the cells remaining were nonfunctional since the threshold of DPOAEs, which are a measure of $\mathrm{OHC}$ functionality as nonlinear amplifiers (Kemp, 2002), were elevated throughout the frequency range and by $60 \mathrm{~dB}$ at low frequencies (Fig. 2C). There was loss of fewer IHCs compared with OHCs (Fig. 2A,D), although as described later, all hair cells were probably non-transducing at P30.

The consequences of the p.T416K mutation for transduction were studied by recording MET currents at the end of the first postnatal week when MET channel development was complete and currents were maximal, but the hair bundles still appeared normal (Beurg et al., 2018). Measurements were taken on a Tmc2-I - background to extract the specific transducer effects of the mutation and rule out the contribution of TMC2. In extracellular $1.5 \mathrm{mM} \mathrm{Ca}^{2+}$ the maximum MET current in apical OHCs of Tmc1 p.T416K/T416K homozygotes was $1.15 \pm$ $0.10 \mathrm{nA}(N=18)$, not significantly different from the control current in $T m c 1+/+$ mice, which was $1.18 \pm 0.16 \mathrm{nA}(N=14$; Fig. 3). The maximum MET current in basal OHCs of the mutant was $1.39 \pm$ $0.08 \mathrm{nA}(N=5)$, significantly larger than the current in apical OHCs ( $t$ test, $p<0.0005)$, suggesting that the tonotopic gradient was still present in the mutant. When extracellular $\mathrm{Ca}^{2+}$ was reduced to $0.04 \mathrm{~mm}$, as in endolymph (Bosher and Warren, 1978; Ikeda et al., 1987), the maximum current increased by $50 \%$ in both genotypes and a large fraction of the current was turned on at the resting position of the bundle. In the control, the fraction of current open at rest, $\mathrm{P}_{\mathrm{OR}}$, increased as previously reported (Johnson et al., 2011) to $0.44 \pm 0.06(N=8)$, but in the Tmc1 p.T416K/T416K homozygote, the increase in $\mathrm{P}_{\mathrm{OR}}$ was smaller, to $0.22 \pm 0.06(N=6)$, significantly different from the control $(t$ test, $p<0.001$; Fig. 3 ). The difference in resting open probability was not observed in the $1.5 \mathrm{~mm}$ extracellular $\mathrm{Ca}^{2+}$ : in $\mathrm{Tmc1}+/+$, $\mathrm{P}_{\mathrm{OR}}=0.030 \pm 0.01(N=8)$, whereas in Tmc1 p.T416K/T416K, $\mathrm{P}_{\mathrm{OR}}=0.037 \pm 0.03(N=6$; difference not significant: $t$ test, $p=0.45)$. A smaller increase in $\mathrm{P}_{\mathrm{OR}}$ in $0.04 \mathrm{~mm}$ was also seen in Tmc1 p.M412K/M412K, where the $\mathrm{P}_{\mathrm{OR}}$ was $0.19 \pm 0.07(N=7$; Beurg et al., 2015a), suggesting that open channels are less stable at rest.
MET currents were also of normal amplitude in IHCs of Tmc1 p.T416K at P8 (Fig. $4 A, B$ ) and not significantly different from Tmcl $+/+$ control (Fig. $4 C$ ). The transducing ability of both IHCs and OHCs was assessed at P30 using influx of FM143 as a marker of intact MET channels (Gale et al., 2001). The assay was performed on apical hair cells in an unfixed cochlear explant (see Materials and Methods). The fluorescent signal in Tmc1 +/+ hair cells because of FM1-43 entry was approximately halved if the MET channels were blocked with $0.1 \mathrm{~mm} d$-tubocurarine (Glowatzki et al., 1997; Krey et al., 2020). Cell fluorescence was also reduced in both IHCs and OHCs of Tmc1 p.T416K relative to $T m c 1+/+$ (Fig. 4D,E). However, the residual fluorescence in $T m c 1$ p.T416K persisted in the presence of $d$-tubocurarine (Fig. 4E), indicating that MET channels in both types of hair cell are absent in the mutant at P30, corroborating the ABR measurements.

The elementary channel conductance was determined from recording of single channels after severing most of the tip links 

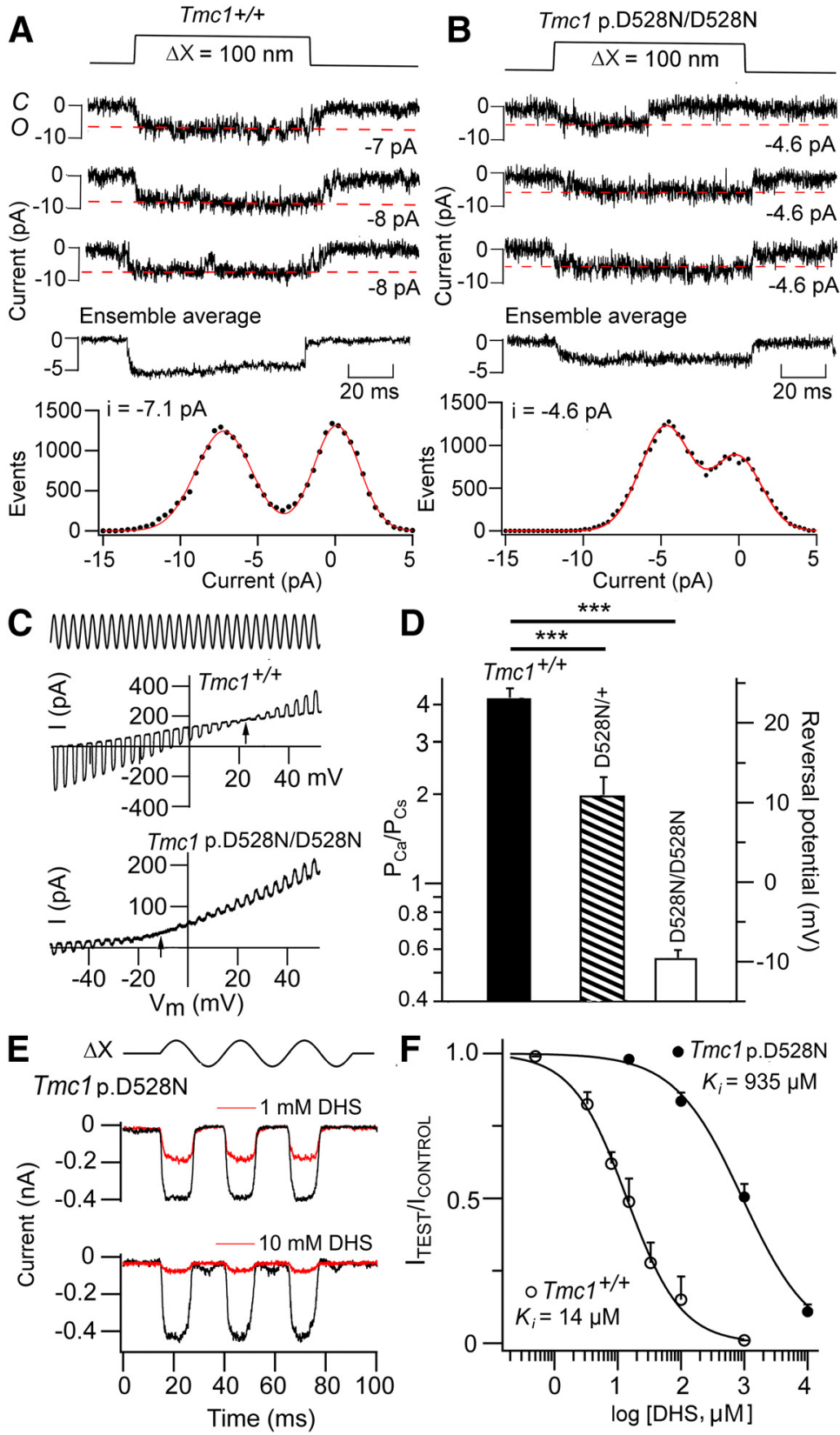

Figure 7. Ionic properties of MET channels from apical OHCs of Tmc1 p.D528N/D528N; Tmc2-/- A, Three examples of single MET channel currents for $\operatorname{TmC} 1+/+$; $\operatorname{TmC}-1-$, ensemble average of 50 presentations (middle) and amplitude histogram (bottom) giving $-7.1 \mathrm{pA}$ at $-84 \mathrm{mV}$. B , Examples of single MET channel currents for Tmc1 p.D528N/D528N; Tmc2-/-, ensemble average of 30 presentations (middle) and amplitude histogram (bottom) giving $-4.6 \mathrm{pA}$ at $-84 \mathrm{mV}$, significantly smaller than control $(p<0.001)$. C, Determination of MET channel $\mathrm{Ca}^{2+}$ permeability in isotonic external $\mathrm{Ca}^{2+}$ and internal $\mathrm{Cs}^{+}$(see Materials and Methods). During a sinusoidal bundle vibration $(\Delta X, \pm 200 \mathrm{~nm})$, the membrane potential $\left(V_{m}\right)$ was swept from -80 to $+80 \mathrm{mV}$ and the MET current reversed polarity at arrowed potential. Reversal potential in Tmc1 p.D528N/D528N; $\operatorname{Tmc} 2-1-$ is $\sim 34 \mathrm{mV}$ negative to $\operatorname{Tmc} 1+/+$; Tmc2-1- indicating much reduced $\mathrm{Ca}^{2+}$ permeability. D, Collected reversal potentials and relative permeability $\mathrm{P}_{\mathrm{Ca}_{\mathrm{a}}} \mathrm{P}_{\mathrm{cs}}$ in four cells each of $\operatorname{Tmc1}+/+, \operatorname{Tmc1} \mathrm{p.D528N}+$ and $\operatorname{Tmc} 1$ p.D528N/D528N. All of which are significantly different $(* * *) p<0.001$. Note the heterozygote reversal potential lies between wild type and homozygote. $\boldsymbol{E}$, MET currents for bundle vibrations $(\Delta X, \pm 200 \mathrm{~nm})$ in normal saline (black traces) and on adding DHS at $1 \mathrm{~mm}$ (top) and $10 \mathrm{~mm}$ (bottom) in Tmc1 p.D528N/D528N; Tmc2-/- (bottom). $\boldsymbol{F}$, Mean \pm SD (N=5) of MET current block by DHS in Tmc1 $+/+(N=5)$ and Tmc1 p.D528N/D528N $(N=3)$. Hill plots give $K_{I}=14 \mu \mathrm{m}$, Hill coefficient $=1$ for control and $935 \mu \mathrm{m}$, Hill coefficient $=0.81$ for mutant.

with submicromolar $\mathrm{Ca}^{2+}$ (Beurg et al., 2006, 2015b). All measurements were performed on Tmc2-I- mice. Recordings from apical OHCs (Fig. 5A,B) gave a unitary current in the OHCs illustrated of $-7.0 \mathrm{pA}$ in $T m c 1+/+$ control and $T m c 1$ p.T416K/ T416K mutant. The mean single-channel conductance averaged over all cells was $84.8 \pm 3.1 \mathrm{pS}(N=5)$ for control and $87.2 \pm 4.5 \mathrm{pS}(\mathrm{N}=4)$ for the mutant (differences not significant; $t$ test, $p=0.35$ ). Thus, the mutation had no effect on the single-channel conductance. The $\mathrm{Ca}^{2+}$ permeability of the MET channel and its susceptibility to block by DHS were also determined and both were reduced in apical OHCs of the Tmc1 p.T416K/T416K. The $\mathrm{Ca}^{2+}$ permeability relative to $\mathrm{Cs}^{+}\left(\mathrm{P}_{\mathrm{Ca}} / \mathrm{P}_{\mathrm{Cs}}\right)$ of the MET channel was determined from the reversal potential of the current in isotonic $\mathrm{Ca}^{2+}$ saline and the permeability was inferred with the GHK equation (Beurg et al., 2006; Kim et al., 2013). The $\mathrm{Ca}^{2+}$ permeability relative to $\mathrm{Cs}^{+}$in $\mathrm{Tmcl}$ p.T416K/ T416K was $2.80 \pm 0.5(N=6)$ compared with $4.25 \pm 0.35(N=8)$ in the control $T m c 1+/+$, the difference being significant ( $t$ test, $p=0.0004$; Fig. $5 C, D)$. Another property of the Tmc1 p.T416K/T416K channels was diminished efficacy of channel block by the aminoglycoside antibiotic DHS, known to enter and block the wild-type MET channel at micromolar concentrations (Marcotti et al., 2005). The half-blocking concentration for DHS was $66 \pm 13 \mu \mathrm{M}$ (four cells per dose) in the Tmc1 p.T416K/T416K mutant mice and $15 \pm 0.7 \mu \mathrm{M}$ (four cells per dose) for the $T m c 1+/+$ control mice (Fig. $5 E, F$ ). Effects on both parameters, a reduction in $\mathrm{Ca}^{2+}$ permeability and decreased potency of extracellular DHS, were also observed in the mutation Tmc1 p.M412K/M412K (Beurg et al., 2015a; Corns et al., 2016).

\section{Tmc1 p.D528N and Tmc1 p.W554L mutations}

We characterized the transducing abilities in two other Tmc1 mouse mutants, Tmcl p. D528N and Tmc1 p.W554L. Tmc1 p.D528N is a new missense mutation leading to the substitution of an asparagine for the negatively charged aspartate in TM6 using the current model of TMC1 (Ballesteros et al., 2018). Tmc1 p.W554L mutation was previously reported as the stitch mutant mouse arising from N-ethyl-N-nitrosourea mutagenesis (Manji et al., 2012), and affects an aromatic residue located at the intracellular loop between TM6 and TM7. Both were recessive deafness-causing mutations (Fig. 6) but had different severity. In Tmc1 p.D528N mutant mice, there was no ABR at P30 and there was loss of cochlear hair cells, more prominent in basal OHCs and throughout the cochlea in IHCs (Fig. 6A,B). In the Tmc1 p.W554L mutants the ABR had some low frequency response at $\mathrm{P} 30$, but no response was evident at P60 (Fig. 6D). There was also no IHC or OHC loss at P30 but basal and mid-region OHCs had degenerated by P60 (Fig. 6E). The delayed effects on the ABR and OHC loss both indicate that the Tmc1 p.W554L mutation is progressive. 
Mechanotransduction was assayed in apical OHCs of Tmc1 p.D528N mice at the end of the first postnatal week P5-P7. Several significant changes were found including a large reduction in $\mathrm{Ca}^{2+}$ permeability and importantly a reduction in single-channel conductance. Single channel currents were recorded in OHCs (Fig. $7 A, B)$, those illustrated having amplitudes at $-84 \mathrm{mV}$ of $7.1 \mathrm{pA}$ in the $T m c 1+/+$ control and $4.6 \mathrm{pA}$ in the Tmc1 p.D528N/ D528N mutant. Mean conductance values were $84.8 \pm 3.1 \mathrm{pS}(N=5)$ in the control and $53.5 \pm 2.9 \mathrm{pS}(N=5)$ in the mutant, a significant difference ( $t$ test, $p=0.001$ ) corresponding to a $37 \%$ reduction in conductance relative to the control. The macroscopic MET current was about half the size of the controls $(0.55 \pm 0.05 \mathrm{nA}$, $N=11$; difference significant, $p=0.001)$ in apical OHCs and smaller $(0.39 \pm 0.11 \mathrm{pA}$, $N=3)$ in P8 Tmc1 p.D528N/D528N control IHCs than in Tmcl $+/+$ controls IHCs $(0.59 \pm 0.06 \mathrm{pA}, N=5$; Fig. $4 C)$. The reduced macroscopic current is largely explained by smaller single-channel conductance rather than by a reduced number of channels in the bundle. The $\mathrm{Ca}^{2+}$ permeability $\left(\mathrm{P}_{\mathrm{Ca}} / \mathrm{P}_{\mathrm{Cs}}\right.$; Fig. $\left.7 C, D\right)$ was reduced 7 -fold relative to control from $4.25 \pm 0.35$ $(N=8)$ to $0.57 \pm 0.04(N=7)$ in the homozygotes, Tmc1 p.D528N/D528N. We also characterized the heterozygote Tmcl p. $\mathrm{D} 528 \mathrm{~N} /+$; and found an intermediate reduction to $2.00 \pm 0.33(N=6)$, which is about half-way between the wild type and homozygote. Despite the large decrease in $\mathrm{Ca}^{2+}$ permeability, there was no effect on the external $\mathrm{Ca}^{2+}$ block, and the current amplitude increased to $1.48 \pm 0.19(N=4)$ on lowering external $\mathrm{Ca}^{2+}$ from $1.5 \mathrm{~mm}$ to $0.04 \mathrm{~mm}$. Nor was there a large effect of the mutation on the $\mathrm{P}_{\mathrm{OR}}$, which was $0.39 \pm 0.01(N=4)$ in the homozygote.

Compared with Tmc1 p.T416K/T416K, there was an even larger 67 -fold reduction in the effectiveness of DHS to block the MET channel in Tmc1 p.D528N/D528N. The half-blocking concentration for DHS was $925 \pm 95 \mu \mathrm{M}(N=3$ cells per dose) for the homozygous p.D528N mutant compared with $15 \pm 0.7 \mu \mathrm{M}(N=4$ cells per dose) for the control Tmc1+/t mice (Fig. 7E,F). Both the reduction in $\mathrm{Ca}^{2+}$ permeability and decreased potency of extracellular DHS were seen in the Tmc1 p.M412K/ M412K mutation (Beurg et al., 2015a; Corns et al., 2016), but the effects of p.D528N were in both cases much larger. The effect of p.D528N may be partly attributable to restricting DHS access into the pore.

The consequences of the missense mutation Tmc1 p.W554L/ W554L were less severe than for the other mutants studied. There was a reduction in the maximum current, up to $60 \%$, at both the apex and base (Fig. $8 A, B$ ). The maximum MET current in OHCs developed over the first week, becoming maximal at P4 at the base of the cochlea and P6 at the apex. Unlike Tmc1 p.
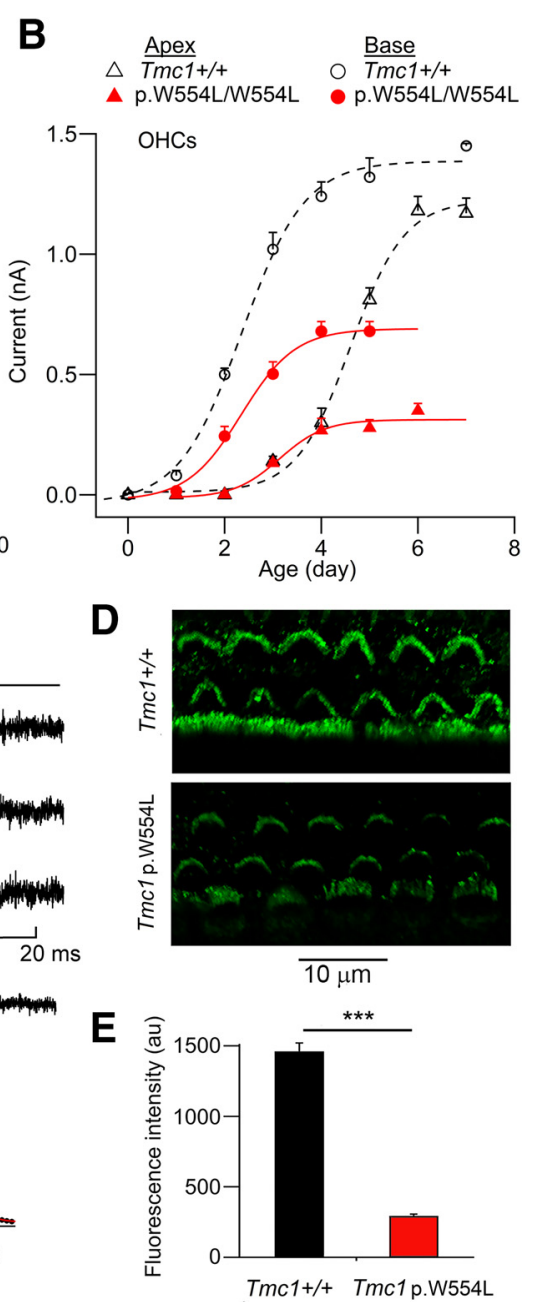

Figure 8. MET currents from OHCs of Tmc1 p.W554L/W554L; Tmc2-/-. A, Maximum currents in Tmc1+/+ (black traces) and Tmc1 p.W554L/W554L (red traces) for hair bundle vibrations $(\Delta \mathrm{X}, \pm 200 \mathrm{~nm})$ in apical and basal $0 \mathrm{HCs}$. $\boldsymbol{B}$, Neonatal development of MET current (mean $\pm S D, N=6$ ) for basal and apical OHCs. Note the basal OHC currents develop mum currents are up to 6-fold smaller. C, Examples of single MET channel currents for Tmc1 p.W554L/W554L; Tmc2-/-, ensemble average of 30 presentations (middle) and amplitude histogram (bottom) giving single channel $-7.2 \mathrm{pA}$. Holding p.W554L/W554L; Tmc2 - / - (bottom). E, Collected measurements of fluorescent intensity (au) in Tmc1+/+; Tmc2-/Measurements made on 115 cells (control) and 75 cells (mutant) of four mice.

D569N (Beurg et al., 2019), tonotopy was preserved and the maximum current although reduced was still larger at the base than at the apex. In contrast, there was no effect on single channel current (Fig. 8C), the mean unitary conductance being $88.3 \pm 4.0 \mathrm{pS}(\mathrm{N}=4)$, not significantly different from $T m c 1+/+$ $84.8 \pm 3.1 \mathrm{pS}(N=5 ; t$ test, $p=0.52)$. Furthermore, there was only a modest change in $\mathrm{Ca}^{2+}$ permeability with $\mathrm{P}_{\mathrm{Ca}} / \mathrm{P}_{\mathrm{Cs}}=$ $3.59 \pm 0.27(N=8)$. The reduction in maximum MET current in the mutant is attributable to a decrease in the channel expression at the transduction site. The number of functional MET channels was inferred from the ratio of the macroscopic to single-channel currents. Thus, the number of active MET channels was $58 \pm 13(N=4)$ in $T m c 1$ p.W554L/W554L compared with $166 \pm 23(N=5)$ in $T m c 1+/+$. The reduction in channel number was confirmed by immunolabeling for TMC1 (Fig. $8 D$ ), showing bundle labeling intensity was reduced 5-fold, a significant change ( $t$ test, $p=0.001$ ) in Tmc1 p.W554L/ W554L compared with Tmc1+/+ (Fig. 8E). 



Figure 9. Loss of mechanotransduction determined with FM1-43 influx. A, Fluorescence images showing one row of IHCs and three rows of OHCs in the apical turn of cochlear explants of P15 Tmc1 p.T416K/T416k; Tmc2-/- mice after exposure to $6 \mu \mathrm{m}$ FM1-43 in the absence (top) and presence (bottom) of $0.1 \mathrm{~mm}$ curare. $\boldsymbol{B}$, Fluorescence intensity in $\mathrm{HCS}$ and $\mathrm{OHCs}$ with and without $d$-tubocurarine in P15 mice (left) and P21 mice (right). Number of cells measured ( \pm curare): P15 IHCs 76, 65; P15 OHCs 120, 145; P21 IHCs 55, 50; 0HCs 69, 72. C, Fluorescence images in apical turns of P15 Tmc1 p.D528N/D528N; TmC2 - - - mice after exposure to $6 \mu \mathrm{m}$ FM1-43 in the absence (top) and presence (bottom) of $0.1 \mathrm{~mm}$ curare. D. Fluorescence intensity in IHCs and OHCs $\pm \mathrm{Cu}-$ rare in P15 mice (left) and P21 mice (right). Number of cells measured ( \pm curare): P15 IHCs 81, 80; P15 OHCs 278, 178; P21 IHCs 25,$24 ; 0 H C s 68,61$. The small number of P21 IHCs reflect loss of these cells. All IHC measurements were made at slightly different focal plane to $\mathrm{OHCs} ; * *$ statistical significance indicated $t$ test, $p<0.001$, in panles $\boldsymbol{B}-\boldsymbol{D}$, bars denote mean $+/-\mathrm{SD}$.

The timetable for transduction loss

The time course for disappearance of mechanotransduction was documented in Tmc1 p.T416K/T416K and in Tmc1 p.D528N/ $\mathrm{D} 528 \mathrm{~N}$ to address possible mechanisms underlying hair cell loss in the Tmc1 mutants. Based on electrophysiological recordings, both genotypes are known to possess functional MET channels in the early postnatal period at P5-P8 (Figs. 3, 4, 7), but based on ABR measurements, those mice were deaf by P30 (Figs. 2B, 6B). We examined transduction in the third postnatal week, after the onset of hearing at P12. It was difficult to use ABRs on mice of this age range, so instead we employed the Preyer (pinna twitch) reflex to test whether hearing was present (see Materials and Methods). With this method, Tmc1 p.T416K/T416K were all still hearing at P15 (6/6 mice positive reflex) but not at P20 (0/4 mice positive), whereas some Tmc1 p.D528N/D528N mice were deaf at P15 (5/9 mice positive reflex) and all at P21 (0/8 mice positive). To determine whether deafness was associated with loss of mechanotransduction at these ages, hair cell fluorescence because of the influx of FM1-43 through the MET channels was used to reveal functional channels (Gale et al., 2001; Meyers et al., 2003; Fig. 9). In these experiments, FM1-43 was perfused into the apical turn of temporal bone explants in the presence or absence of MET channel blockers; the solution perfused was ice cold to minimize energy-dependent uptake of the dye by endocytic processes (Vélez-Ortega et al., 2017). For Tmc1 p.T416K/ T416K mice, FM1-43 fluorescence was partially suppressed in IHCs and OHCs in P15 cochleas after blocking the channels with $0.1 \mathrm{~mm} d$-tubocurarine; this finding shows that both hair cell types transduce at P15. However, by P21, significant transduction was present in $\mathrm{OHCs}$ but not in IHC (Fig. 9B). For Tmc1 p. D528N/D528N mice, significant transduction occurred in both IHCs and $\mathrm{OHCs}$ at $\mathrm{P} 15$, but in neither cell type by P21 (Fig. 9D). We conclude from these observations that mechanotransduction was lost in the mutants between P15 and $\mathrm{P} 21$. At this time in wild-type mice, the endocochlear potential attains its maximal value (Steel and Barkway, 1989) and hearing sensitivity grows toward its adult level (Ehret, 1976).

\section{Conclusions}

The properties of functional MET channels in the five mutations, characterized at P6 in apical OHCs, are collected in Table 1 and include single-channel conductance, $\mathrm{Ca}^{2+}$ permeability and the numbers of "active" channels, $\mathrm{N}_{\mathrm{MET}}$. The damage to, or loss of, cells at P30 is directly related to the decrease in $\mathrm{Ca}^{2+}$ permeability. In order of severity, $\mathrm{D} 528 \mathrm{~N}>\mathrm{D} 569 \mathrm{~N}>\mathrm{M} 412 \mathrm{~K}>\mathrm{T} 416 \mathrm{~K}$ $>$ W554L. $\mathrm{N}_{\text {MET }}$ represents the number of MET channels recruitable by bundle stimulation and was determined as the ratio of the macroscopic to single-channel conductance. It is noteworthy that $\mathrm{N}_{\text {MET }}$ values congregate in two categories, those $\sim 123-166$ and those below 100. Another mutation in the latter category besides the Tmc1 p.W554L/W554L is at a nearby intracellular site Tmc1 p.D569N/D569N (Beurg et al., 2019) and had $46 \pm 18(N=5)$ channels. An additional point worth noting from Table 1 is that all dominant mutations, M412K, T416K, and D569N, show a significantly smaller $\mathrm{P}_{\mathrm{OR}}$ in $0.04 \mathrm{mM} \mathrm{Ca}^{2+}$ than the control. This distinction may provide some clue to the origin of dominant and recessive deafness mutations. However, it is important to note that none of the mutations studied abolished $\mathrm{Ca}^{2+}$ block of the channel, which is a distinct property independent of $\mathrm{Ca}^{2+}$ permeation.

\section{Discussion}

We have examined the relation between TMC1 and hair cell transduction by characterizing five missense mutations in the region of the protein, within TM4-TM7, that has been proposed to form the ion conducting pore (Ballesteros et al., 2018; Pan et al., 2018). We described a new dominant human deafness mutation TMC1 p.T422K and studied the mechanistic consequences in the homologous mouse mutant Tmc1 p.T416K. We characterized mechanotransduction in this mutant mainly in OHCs at the end of the first postnatal week when there were no noticeable morphologic changes in the hair bundles or cell body. The T416K mutation site is near the Beethoven mutation M412K (Vreugde et al., 2002; Marcotti et al., 2006), one turn of the TM4 $\alpha$-helix closer to the intracellular side of the membrane (Fig. $10 A, B)$. These two mutations substitute a positively charged for an uncharged residue and have similar effects on the MET channels, including a reduced $\mathrm{Ca}^{2+}$ permeability of the channel, a lower resting open probability, $\mathrm{P}_{\mathrm{OR}}$, in $0.04 \mathrm{mM} \mathrm{Ca}^{2+}$ (similar to 
Table 1. Ionic properties of the MET channel in P5-P7 apical OHCs from mice with Tmc1 missense mutations, all of which cause deafness

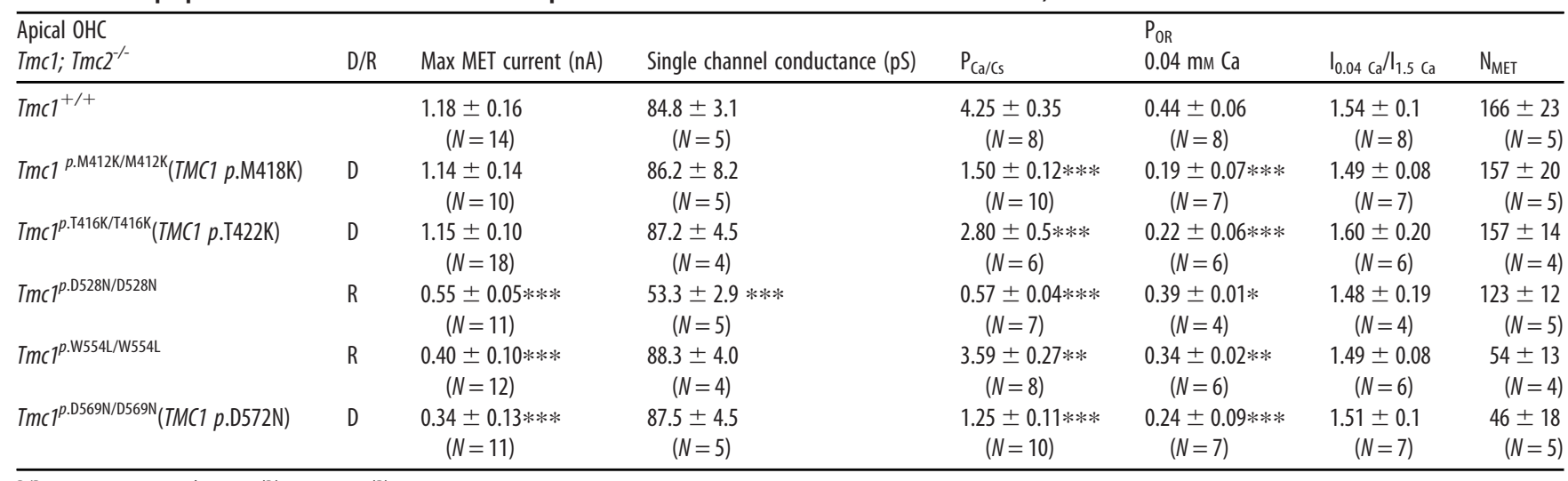

$\mathrm{D} / \mathrm{R}$, mutations are semi-dominant $(\mathrm{D})$ or recessive $(\mathrm{R})$

$\mathrm{P}_{\mathrm{OB}}$ is resting open probability in $0.04 \mathrm{~mm}$ extracellular $\mathrm{Ca}^{2+}$. I increase is current ratio in 0.04 and $1.5 \mathrm{~mm} \mathrm{Ca}^{2+}$. Nuct number of MET channels is ratio of maximum to single-channel current, SD determined by max current. Each value mean \pm SD. Mouse mutations (column 1) also show existing homologous human mutations. Human TMC1 numbering, with total 761 aa, differs from neonatal mouse with 757 aa. Significance tests between mutants and control $(\operatorname{Tmc} 1+/+) t$ test: $* p<0.05, * * p<0.01, * * * p<0.001$. Unstarred values were not significantly different from control $\operatorname{Tmc} 1+/+$, with $p>0.2$.

its concentration in endolymph; Bosher and Warren, 1978) and a smaller susceptibility to block by the aminoglycoside antibiotic DHS. These three properties had been previously documented for the Beethoven mutation Tmc1 p.M412K (Beurg et al., 2015a; Corns et al., 2016). For neither mutant was there an alteration in the single-channel conductance or in the maximum MET current, reflecting an unchanged number of channels in the hair bundle. Besides T416K (human TMC1 p.G4226R) and the M412K (human TMC1 p.G418K), there are two other neighboring human deafness mutations, TMC1 p.G416R and TMC1 p.L417R, the functional effects of which in mice would be worth studying. Together the effects of these mutations suggest that there is a region of TM4 influencing ion transport. In each case, the deleterious effect of adding a positively charged residue, either lysine $(\mathrm{K})$ or arginine $(\mathrm{R})$, implies an important role of the cavity electrostatics for ion selectivity. The positive charges might depress $\mathrm{Ca}^{2+}$ permeation or binding of the cationic DHS. Alternatively, the region of TM4 containing residues 410-416 may constitute the site of interaction of TMC1 with another pore-forming or accessory protein, such as TMIE (Cunningham et al., 2020) or the lipid membrane, and alteration of these interactions could influence the ion selectivity and the open-closed equilibrium.

Only two of the mutations, Tmc1 p.W554L/W554L and Tmc1 p.D569N/D569N, showed significantly reduced expression of functional channels in the bundle, $\mathrm{N}_{\text {MET }}$ (Fig. $8 D$; Table 1). It has been proposed that D569 is the site of interaction of TMC1 with the accessory protein LHFPL5 (Yu et al., 2020) and that the mutation p.D569N impairs this interaction. Since LHFPL5 is required to transport TMC1 into the bundle (Beurg et al., 2015b), reduced interaction between the two proteins is predicted to diminish channel density as observed. Consistent with this notion, we suggest that residue W554 is also within the TMC1-LHFPL5 interaction region. The explanation for the reduced $\mathrm{P}_{\mathrm{Ca}}$ in Tmc1 p.W554L/W554L is unclear because the residue is not in the pore cavity according to modeling (Fig. 10A,B). LHFPL5 may also be a conduit for force to gate the channel since it strongly interacts with the tip link protein PCDH15 (Xiong et al., 2012; Ge et al., 2018). In membrane proteins, tryptophans near the lipidwater interface are thought to interact with the membrane playing an anchoring role (Sanchez et al., 2011; de Jesus and Allen, 2013). The W554L mutation could affect the interaction of the TM6-TM7 loop with the membrane destabilizing this loop and affecting protein stability and folding.

Of the five mutations studied, Tmc1 p.D528N/D528N has the most severe effects on ion permeation, being the only one to show a reduction (of 37\%) in unitary conductance and a large 7 fold reduction in $\mathrm{Ca}^{2+}$ permeability; together, these changes are predicted to produce a 10 -fold reduction in resting $\mathrm{Ca}^{2+}$ influx, more than in any of the other mutations. Furthermore, there was a large, $\sim 70$-fold, reduction in effectiveness of DHS to block the MET channel. According to recent modeling (Ballesteros et al., 2018), the amino acid D528 is near the extracellular side of TM6 in a narrow region of the cavity of a hypothetical channel formed by TMC1 (Fig. 10B). The effect on the channel's conductance observed in the D528N mutant could be explained by the removal of a negative charge at this narrow region of the cavity (pore radius of $\sim 0.65 \mathrm{~nm}$ ), which would hinder cationic currents (Fig. $10 A-C$ ). The localization of this aspartate and the severe effects on channel properties implies an important role of this region in ion permeation. In contrast, D569 at the beginning of TM7 and M412 and T416 in the middle of TM4 are facing the wider intracellular region of the cavity with a pore radius of $\sim 1.1$ and $0.9 \mathrm{~nm}$, respectively (Fig. 10C). This wider intracellular region would allow ions to permeate more freely or to interact with several water molecules preserving the channel conductance in the p.T416K, p.M412K, and p.D569N mutants. Addition of a positively charged amino acid (M412K or T416K) or the removal of a negatively charged (D569N or D528N) amino acid reduced $\mathrm{Ca}^{2+}$ selectivity (Beurg et al., 2019), corroborating the important role of charges along the ion-conducting cavity for preferential selectivity for $\mathrm{Ca}^{2+}$ over other cations.

The main aim of our work has been to link mutations causing single amino acid replacements to MET channel structure and performance. The effects of the mutations are consistent with the present view of TMC1 as the primary structural component of the MET channel, with the region of TM4 to TM7 determining its ionic permeability properties (Ballesteros et al., 2018; Pan et al., 2018). The mutations demonstrate that both the $\mathrm{Ca}^{2+}$ permeability and unitary conductance can be altered by single aminoacid substitution and they suggest TMC1 binding to at least one other accessory protein LHFPL5. However, an unanswered question is what connects these relatively small alterations in channel 
A

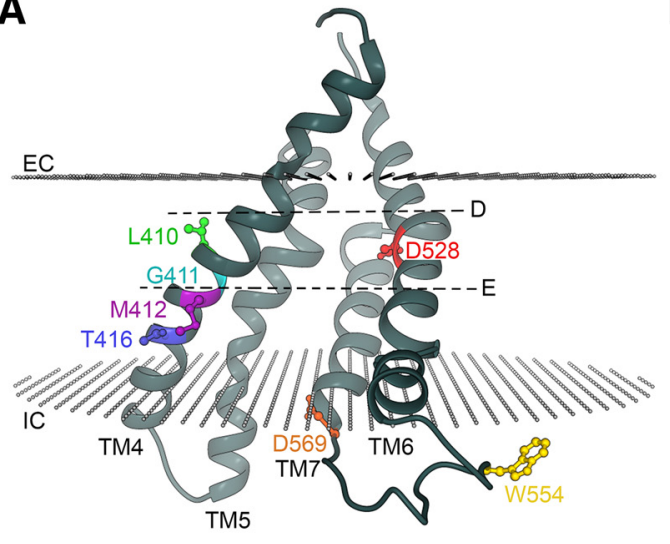

C

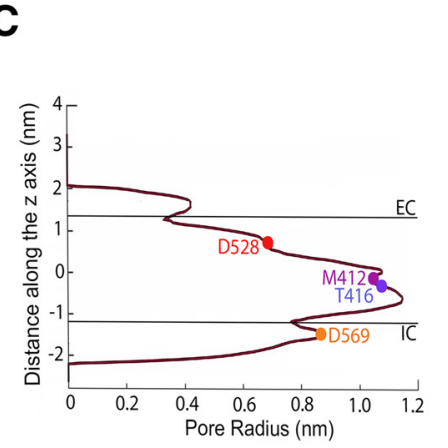

D
B

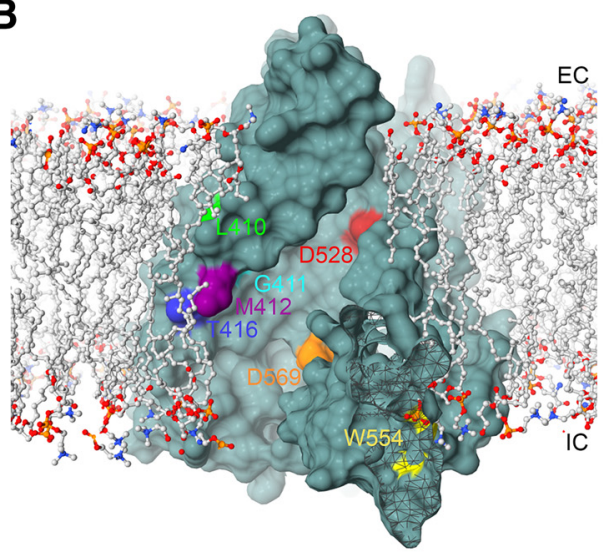

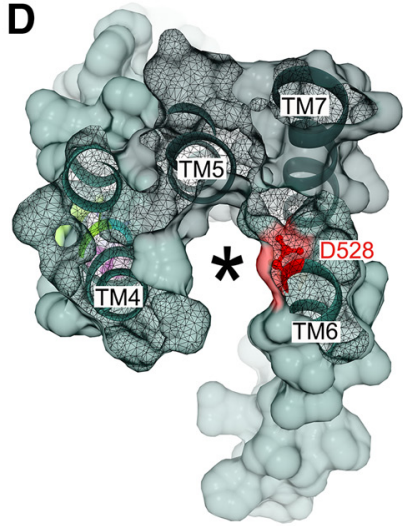

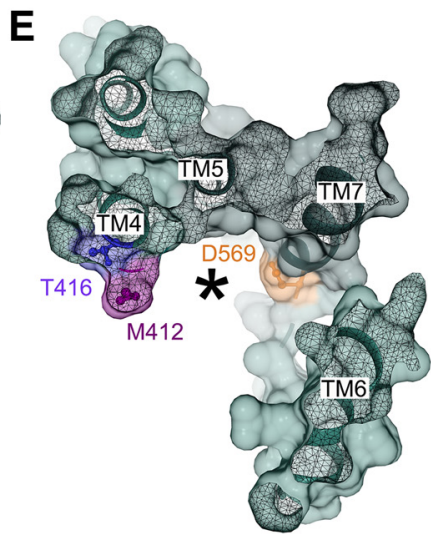

Figure 10. Localization of deafness-causing mutations in TMC1. A, Ribbon representation of the TMC1 cavity built by TM domains TM4-TM7. The side chains of residues L410 (green), G411 (cyan), M412 (magenta), T416 (blue), D528 (red), W554 (yellow), and D569 (orange) are depicted in ball and stick representation. The approximated location of the lipid carbonyls of the plasma membrane is represented with two planes of gray spheres and the intracellular $(\mathrm{IC})$ and extracellular $(\mathrm{EC})$ sides are indicated. $\mathrm{D}$ and $\mathrm{E}$ dashed lines indicate the planes shown in panels $\boldsymbol{D}, \boldsymbol{E}$, respectively. B, Surface representation of the TMC1 ion conduction cavity embedded in a lipid membrane. Residues L410, G411, M412, T416, D528, W554, and D569 are colored as in $\boldsymbol{A}$. Phospholipids are shown in ball and stick representation with their aliphatic chain in gray, phosphate in orange, oxygen in red, and nitrogen in blue. C, Pore profile along the cavity indicating the approximated positions of the EC and IC and residues M412, T416, D528, and D569. D, Surface representation of the top view of the TM4-TM7 cavity from the extracellular side revealing the localization of D528 (red) at its narrower region. $E$, Surface representation of the top view of the cavity from the extracellular side revealing the localization of D569 (orange), T416 (blue), and M412 (magenta) at the wider region of the cavity. The asterisks in $\boldsymbol{D}, \boldsymbol{E}$ indicate the potential ion permeation pathway.

properties to subsequent hair cell death and deafness. Clearly all channel variants are manufactured in the endoplasmic reticulum (ER) and transported to the tips of the stereocilia where they behave as functional transducer channels, at least in the first postnatal week. Although for two of the mutants, D569N and W554L, fewer channels are ferried to the transduction site, those that are delivered are fully operative at P6. What then causes the MET channels to lose functionality during subsequent development?

One possible pathway, common to all variants, is a decrease in $\mathrm{Ca}^{2+}$ permeability, which in $\mathrm{D} 528 \mathrm{~N}$ is exacerbated by concomitant reduction in channel conductance, diminishing $\mathrm{Ca}^{2+}$ influx into the stereocilia. The reduced $\mathrm{Ca}^{2+}$ influx may fail to maintain actin polymerization at the stereociliary tips (VélezOrtega et al., 2017) and eventually lead to hair bundle disorganization. In support of this idea, the severity of the mutation, judged by hair cell death at P30, roughly follows the degree of reduction in $\mathrm{Ca}^{2+}$ permeability. For example, D528N shows the greatest change in $\mathrm{Ca}^{2+}$ selectivity and largest hair cell loss (which includes IHCs) at P30, and W554L the least, with no hair cell loss until P60 (Fig. 6), D569N is intermediate with some IHC loss (Beurg et al., 2019; their Fig. 1E). However, this cannot be the whole explanation because all mutants eventually become deaf. A second factor may be the resting open probability in 0.04 $\mathrm{mm}$ (endolymph-like) $\mathrm{Ca}^{2+}$ which is significantly reduced in the dominant mutations M412K, T416K, and D569N. The main consequence will be a smaller inward current through the open MET channels in vivo, causing hyperpolarization of the hair cell resting potential (Johnson et al., 2011). This effect would assume importance in the week after the onset of hearing, P12-P19, when the endolymphatic potential climbs to its maximum of $100 \mathrm{mV}$ (Steel and Barkway, 1989; Li et al., 2020) and as a consequence endolymphatic $\mathrm{Ca}^{2+}$ decreases (Johnson et al., 2012). The endolymphatic $\mathrm{Ca}^{2+}$ concentration is partly determined by a passive distribution of the ion between the endolymph and perilymph and can be calculated from the Nernst equation: $\mathrm{V}_{\mathrm{EP}}=$ $30 \log _{10}\left(\mathrm{Ca}_{\mathrm{P}} / \mathrm{Ca}_{\mathrm{E}}\right)$, where $\mathrm{Ca}_{\mathrm{P}}$ and $\mathrm{Ca}_{\mathrm{E}}$ are the $\mathrm{Ca}^{2+}$ concentrations in the perilymph and endolymph, respectively and $V_{E P}$ is the endocochlear potential. Thus, as $\mathrm{V}_{\mathrm{EP}}$ increases from 0 to $100 \mathrm{mV}$, the passive component of $\mathrm{Ca}_{\mathrm{E}}$ should decrease causing an increase in the fraction of MET channels open at rest with non-mutant channels. A third class of mechanism relating the mutations to the hair cell death may be impaired processing of mutant TMC1 in the ER. The reduced $\mathrm{Ca}^{2+}$ permeability of the nascent channels may affect ER stress (Krebs et al., 2015) or cytoplasmic $\mathrm{Ca}^{2+}$ homeostasis. There is no direct evidence for this last mechanism, but it may influence proper development of the hair cells (Jeng et al., 2020). For example, it is known that in the Beethoven mutation, Tmc1 p.M412K, the voltage-dependent $\mathrm{K}^{+}$ currents in both IHCs and OHCs are reduced in amplitude, 
more so in the homozygote than in the heterozygote (Marcotti et al., 2006). The factors regulating hair cell maturation are still poorly understood, and more experiments are needed to discriminate between the pathways linking MET channel function and hair cell apoptosis.

\section{References}

Assad JA, Shepherd GM, Corey DP (1991) Tip-link integrity and mechanical transduction in vertebrate hair cells. Neuron 7:985-994.

Ballesteros A, Fenollar-Ferrer C, Swartz KJ (2018) Structural relationship between the putative hair cell mechanotransduction channel TMC1 and TMEM16 proteins. Elife 7:e38433.

Beurg M, Evans MG, Hackney CM, Fettiplace R (2006) A large-conductance calcium-selective mechanotransducer channel in mammalian cochlear hair cells. J Neurosci 26:10992-11000.

Beurg M, Fettiplace R, Nam JH, Ricci AJ (2009) Localization of inner hair cell mechanotransducer channels using high-speed calcium imaging. Nat Neurosci 12:553-558.

Beurg M, Goldring AC, Fettiplace R (2015a) The effects of Tmc1 Beethoven mutation on mechanotransducer channel function in cochlear hair cells. J Gen Physiol 146:233-243.

Beurg M, Xiong W, Zhao B, Müller U, Fettiplace R (2015b) Subunit determination of the conductance of hair-cell mechanotransducer channels. Proc Natl Acad Sci USA 112:1589-1594.

Beurg M, Cui R, Goldring AC, Ebrahim S, Fettiplace R, Kachar B (2018) Variable number of TMC1-dependent mechanotransducer channels underlie tonotopic conductance gradients in the cochlea. Nat Commun 9:2185.

Beurg M, Barlow A, Furness DN, Fettiplace R (2019) A Tmcl mutation reduces calcium permeability and expression of mechanoelectrical transduction channels in cochlear hair cells. Proc Natl Acad Sci USA 116:20743-20749.

Bosher SK, Warren RL (1978) Very low calcium content of cochlear endolymph, an extracellular fluid. Nature 273:377-378.

Chen Y, Wang Z, Wang Z, Chen D, Chai Y, Pang X, Sun L, Wang X, Yang T, $\mathrm{Wu} \mathrm{H}$ (2015) Targeted next-generation sequencing in Uyghur families with non-syndromic sensorineural hearing loss. PLoS One 10:e0127879.

Corns LF, Johnson SL, Kros CJ, Marcotti W (2016) Tmcl point mutation affects $\mathrm{Ca} 2+$ sensitivity and block by dihydrostreptomycin of the mechanoelectrical transducer current of mouse outer hair cells. J Neurosci 36:336-349.

Crawford AC, Fettiplace R (1985) The mechanical properties of ciliary bundles of turtle cochlear hair cells. J Physiol 364:359-379.

Cunningham CL, Qiu X, Wu Z, Zhao B, Peng G, Kim YH, Lauer A, Müller U (2020) TMIE defines pore and gating properties of the mechanotransduction channel of mammalian cochlear hair cells. Neuron 107:126-143.e8.

de Jesus AJ, Allen TW (2013) The role of tryptophan side chains in membrane protein anchoring and hydrophobic mismatch. Biochim Biophys Acta 1828:864-876.

Ehret G (1976) Development of absolute auditory thresholds in the house mouse (Mus musculus). J Am Audiol Soc 1:179-184.

Fettiplace R (2017) Hair cell transduction, tuning, and synaptic transmission in the mammalian cochlea. Compr Physiol 7:1197-1227.

Fettiplace R, Nam JH (2019) Tonotopy in calcium homeostasis and vulnerability of cochlear hair cells. Hear Res 376:11-21.

Gale JE, Marcotti W, Kennedy HJ, Kros CJ, Richardson GP (2001) FM1-43 dye behaves as a permeant blocker of the hair-cell mechanotransducer channel. J Neurosci 21:7013-7025.

Ge J, Elferich J, Goehring A, Zhao H, Schuck P, Gouaux E (2018) Structure of mouse protocadherin 15 of the stereocilia tip link in complex with LHFPL5. Elife 7:e38770.

Giese APJ, Tang YQ, Sinha GP, Bowl MR, Goldring AC, Parker A, Freeman MJ, Brown SDM, Riazuddin S, Fettiplace R, Schafer WR, Frolenkov GI, Ahmed ZM (2017) CIB2 interacts with TMC1 and TMC2 and is essential for mechanotransduction in auditory hair cells. Nat Commun 8:43.

Glowatzki E, Ruppersberg JP, Zenner HP, Rüsch A (1997) Mechanically and ATP-induced currents of mouse outer hair cells are independent and differentially blocked by d-tubocurarine. Neuropharmacology 36:12691275 .
Ikeda K, Kusakari J, Takasaka T, Saito Y (1987) The Ca2+ activity of cochlear endolymph of the guinea pig and the effect of inhibitors. Hear Res 26:117-125.

Jeng JY, Ceriani F, Hendry A, Johnson SL, Yen P, Simmons DD, Kros CJ, Marcotti W (2020) Hair cell maturation is differentially regulated along the tonotopic axis of the mammalian cochlea. J Physiol 598:151-170.

Jo S, Kim T, Iyer VG, Im W (2008) CHARMM-GUI: a web-based graphical user interface for CHARMM. J Comput Chem 29:1859-1865.

Johnson SL, Beurg M, Marcotti W, Fettiplace R (2011) Prestin-driven cochlear amplification is not limited by the outer hair cell membrane time constant. Neuron 70:1143-1154.

Johnson SL, Kennedy HJ, Holley MC, Fettiplace R, Marcotti W (2012) The resting transducer current drives spontaneous activity in prehearing mammalian cochlear inner hair cells. J Neurosci 32:10479-10483.

Kawashima Y, Géléoc GS, Kurima K, Labay V, Lelli A, Asai Y, Makishima T, Wu DK, Della Santina CC, Holt JR, Griffith AJ (2011) Mechanotransduction in mouse inner ear hair cells requires transmembrane channel-like genes. J Clin Invest 121:4796-4809.

Kemp DT (2002) Otoacoustic emissions, their origin in cochlear function, and use. Br Med Bull 63:223-241.

Kim KX, Fettiplace R (2013) Developmental changes in the cochlear hair cell mechanotransducer channel and their regulation by transmembrane channel-like proteins. J Gen Physiol 141:141-148.

Kim KX, Beurg M, Hackney CM, Furness DN, Mahendrasingam S, Fettiplace R (2013) The role of transmembrane channel-like proteins in the operation of hair cell mechanotransducer channels. J Gen Physiol 142:493-505.

Krebs J, Agellon LB, Michalak M (2015) Ca(2+) homeostasis and endoplasmic reticulum (ER) stress: an integrated view of calcium signaling. Biochem Biophys Res Commun 460:114-121.

Krey JF, Chatterjee P, Dumont RA, O'Sullivan M, Choi D, Bird JE, BarrGillespie PG (2020) Mechanotransduction-dependent control of stereocilia dimensions and row identity in inner hair cells. Curr Biol 30:442-454.e7.

Kurima K, Peters LM, Yang Y, Riazuddin S, Ahmed ZM, Naz S, Arnaud D, Drury S, Mo J, Makishima T, Ghosh M, Menon PSN, Deshmukh D, Oddoux C, Ostrer H, Khan S, Riazuddin S, Deininger PL, Hampton LL, Sullivan SL, et al. (2002) Dominant and recessive deafness caused by mutations of a novel gene, TMC1, required for cochlear hair-cell function. Nat Genet 30:277-284.

Laskowski RA, MacArthur MW, Moss DS, Thornton JM (1993) PROCHECK: a program to check the stereochemical quality of protein structures. J Appl Crystallogr 26:283-291.

Li Y, Liu H, Zhao X, He DZ (2020) Endolymphatic potential measured from developing and adult mouse inner ear. Front Cell Neurosci 14:584928.

Lomize MA, Pogozheva ID, Joo H, Mosberg HI, Lomize AL (2012) OPM database and PPM web server: resources for positioning of proteins in membranes. Nucleic Acids Res 40:D370-D376.

Mahendrasingam S, Beurg M, Fettiplace R, Hackney CM (2010) The ultrastructural distribution of prestin in outer hair cells: a post-embedding immunogold investigation of low-frequency and high-frequency regions of the rat cochlea. Eur J Neurosci 31:1595-1605.

Mandelker D, Amr SS, Pugh T, Gowrisankar S, Shakhbatyan R, Duffy E, Bowser M, Harrison B, Lafferty K, Mahanta L, Rehm HL, Funke BH (2014) Comprehensive diagnostic testing for stereocilin: an approach for analyzing medically important genes with high homology. J Mol Diagn 16:639-647.

Manji SS, Miller KA, Williams LH, Dahl HH (2012) Identification of three novel hearing loss mouse strains with mutations in the Tmcl gene. Am J Pathol 180:1560-1569.

Marcotti W, van Netten SM, Kros CJ (2005) The aminoglycoside antibiotic dihydrostreptomycin rapidly enters mouse outer hair cells through the mechano-electrical transducer channels. J Physiol 567:505-521.

Marcotti W, Erven A, Johnson SL, Steel KP, Kros CJ (2006) Tmc1 is necessary for normal functional maturation and survival of inner and outer hair cells in the mouse cochlea. J Physiol 574:677-698.

Meyers JR, MacDonald RB, Duggan A, Lenzi D, Standaert DG, Corwin JT, Corey DP (2003) Lighting up the senses: FM1-43 loading of sensory cells through nonselective ion channels. J Neurosci 23:4054-4065.

Pacentine IV, Nicolson T (2019) Subunits of the mechano-electrical transduction channel, Tmc1/2b, require Tmie to localize in zebrafish sensory hair cells. PLoS Genet 15:e1007635. 
Pan B, Géléoc GS, Asai Y, Horwitz GC, Kurima K, Ishikawa K, Kawashima Y, Griffith AJ, Holt JR (2013) TMC1 and TMC2 are components of the mechanotransduction channel in hair cells of the mammalian inner ear. Neuron 79:504-515.

Pan B, Akyuz N, Liu XP, Asai Y, Nist-Lund C, Kurima K, Derfler BH, György B, Limapichat W, Walujkar S, Wimalasena LN, Sotomayor M, Corey DP, Holt JR (2018) TMC1 forms the pore of mechanosensory transduction channels in vertebrate inner ear hair cells. Neuron 99:736-753.e6.

Pettersen EF, Goddard TD, Huang CC, Couch GS, Greenblatt DM, Meng EC, Ferrin TE (2004) UCSF Chimera-a visualization system for exploratory research and analysis. J Comput Chem 25:1605-1612.

Pickles JO, Comis SD, Osborne MP (1984) Cross-links between stereocilia in the guinea pig organ of Corti, and their possible relation to sensory transduction. Hear Res 15:103-112.

Pugh TJ, Amr SS, Bowser MJ, Gowrisankar S, Hynes E, Mahanta LM, Rehm HL, Funke B, Lebo MS (2016) VisCap: inference and visualization of germ-line copy-number variants from targeted clinical sequencing data. Genet Med 18:712-719.

Ricci AJ, Kennedy HJ, Crawford AC, Fettiplace R (2005) The transduction channel filter in auditory hair cells. J Neurosci 25:7831-7839.

Richards S, Aziz N, Bale S, Bick D, Das S, Gastier-Foster J, Grody WW, Hegde M, Lyon E, Spector E, Voelkerding K, Rehm HL; ACMG Laboratory Quality Assurance Committee (2015) Standards and guidelines for the interpretation of sequence variants: a joint consensus recommendation of the American College of Medical Genetics and Genomics and the Association for Molecular Pathology. Genet Med 17:405-424.

Sanchez KM, Kang G, Wu B, Kim JE (2011) Tryptophan-lipid interactions in membrane protein folding probed by ultraviolet resonance Raman and fluorescence spectroscopy. Biophys J 100:2121-2130.

Steel KP, Barkway C (1989) Another role for melanocytes: their importance for normal stria vascularis development in the mammalian inner ear. Development 107:453-463.

Vélez-Ortega AC, Freeman MJ, Indzhykulian AA, Grossheim JM, Frolenkov GI (2017) Mechanotransduction current is essential for stability of the transducing stereocilia in mammalian auditory hair cells. Elife 6:e24661.

Vreugde S, Erven A, Kros CJ, Marcotti W, Fuchs H, Kurima K, Wilcox ER, Friedman TB, Griffith AJ, Balling R, Hrabé De Angelis M, Avraham KB, Steel KP (2002) Beethoven, a mouse model for dominant, progressive hearing loss DFNA36. Nat Genet 30:257-258.
Wang H, Wu K, Guan J, Yang J, Xie L, Xiong F, Lan L, Wang D, Wang Q (2018) Identification of four TMC1 variations in different Chinese families with hereditary hearing loss. Mol Genet Genomic Med 6:504-513.

Waterhouse A, Bertoni M, Bienert S, Studer G, Tauriello G, Gumienny R, Heer FT, de Beer TAP, Rempfer C, Bordoli L, Lepore R, Schwede T (2018) SWISS-MODEL: homology modelling of protein structures and complexes. Nucleic Acids Res 46:W296-W303.

Wu EL, Cheng X, Jo S, Rui H, Song KC, Dávila-Contreras EM, Qi Y, Lee J, Monje-Galvan V, Venable RM, Klauda JB, Im W (2014) CHARMM-GUI membrane builder toward realistic biological membrane simulations. J Comput Chem 35:1997-2004.

Xiong W, Grillet N, Elledge HM, Wagner TF, Zhao B, Johnson KR, Kazmierczak P, Müller U (2012) TMHS is an integral component of the mechanotransduction machinery of cochlear hair cells. Cell 151:12831295.

Yang J, Yan R, Roy A, Xu D, Poisson J, Zhang Y (2015) The I-TASSER suite: protein structure and function prediction. Nat Methods 12:7-8.

Yang T, Kahrizi K, Bazazzadeghan N, Meyer N, Najmabadi H, Smith RJ (2010) A novel mutation adjacent to the Bth mouse mutation in the TMC1 gene makes this mouse an excellent model of human deafness at the DFNA36 locus. Clin Genet 77:395-398.

Yu X, Zhao Q, Li X, Chen Y, Tian Y, Liu S, Xiong W, Huang P (2020) Deafness mutation D572N of TMC1 destabilizes TMC1 expression by disrupting LHFPL5 binding.Proc Natl Acad Sci USA 117:2989429903.

Yue X, Sheng Y, Kang L, Xiao R (2019) Distinct functions of TMC channels: a comparative overview. Cell Mol Life Sci 76:4221-4232.

Zhao B, Wu Z, Grillet N, Yan L, Xiong W, Harkins-Perry S, Müller U (2014a) TMIE is an essential component of the mechanotransduction machinery of cochlear hair cells. Neuron 84:954-967.

Zhao Y, Wang D, Zong L, Zhao F, Guan L, Zhang P, Shi W, Lan L, Wang H, Li Q, Han B, Yang L, Jin X, Wang J, Wang J, Wang Q (2014b) A novel DFNA36 mutation in TMC1 orthologous to the Beethoven (Bth) mouse associated with autosomal dominant hearing loss in a Chinese family. PLoS One 9:e97064.

Zimmerman RS, Cox S, Lakdawala NK, Cirino A, Mancini-DiNardo D, Clark E, Leon A, Duffy E, White E, Baxter S, Alaamery M, Farwell L, Weiss S, Seidman CE, Seidman JG, Ho CY, Rehm HL, Funke BH (2010) A novel custom resequencing array for dilated cardiomyopathy. Genet Med 12:268-278. 